الثورة الصناعية الرابعة و أدواتها

الثورة الصناعية الرابعة و أدواتها

(HADOOP-SAPHAHN-NOSQL)

أنموذجاً

The fourth industrial revolution and its tools:

( HADOOP-SAPHAHN-NOSQL)

as a model

مدرس المكتبات و المعلومات_كلية الآداب_جامعة أحمد الشـلي

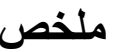

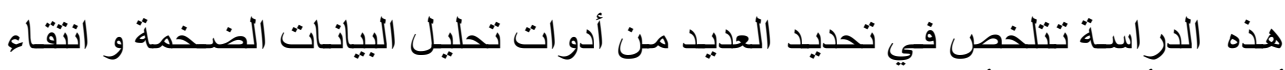

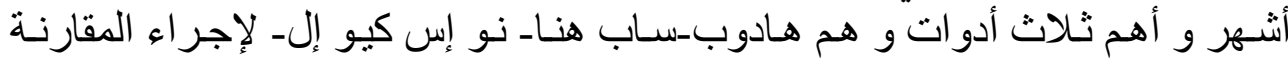

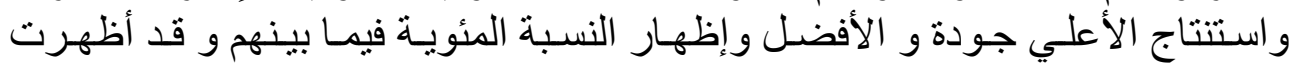

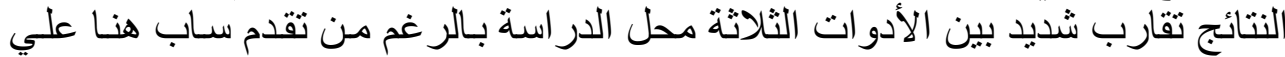

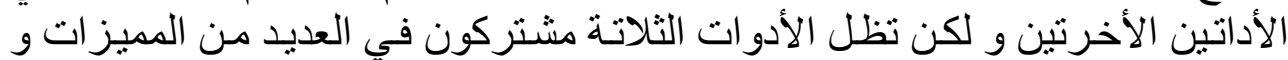

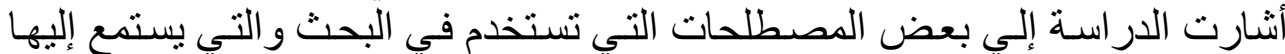

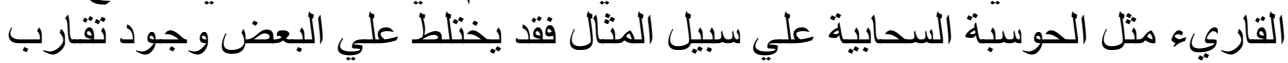

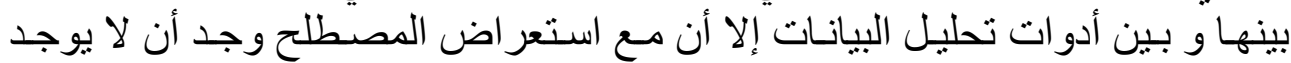

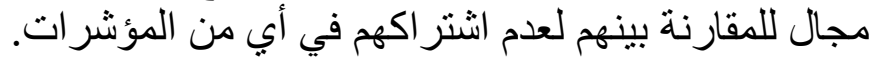

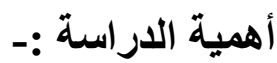

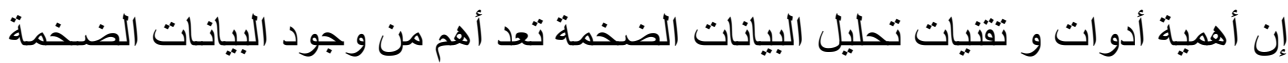

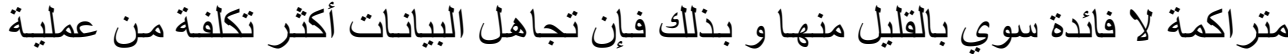

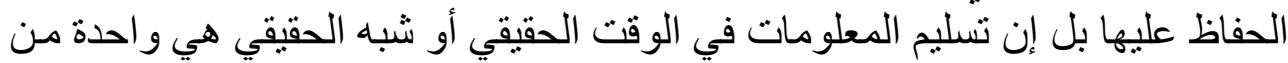

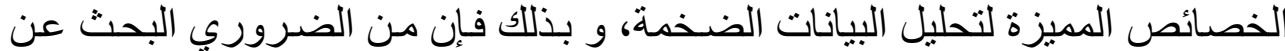

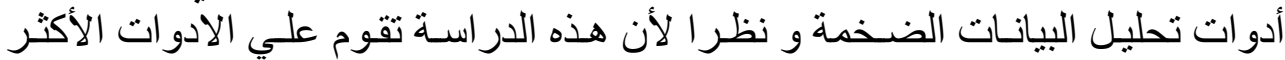

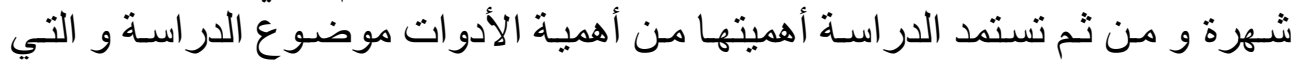

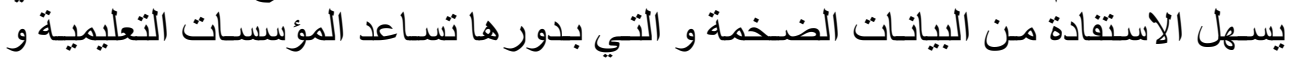

اكتشاف الرؤى المهمة القابلة للتنفيذ . الإنة

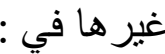

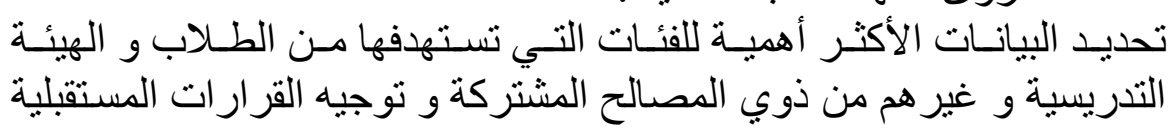




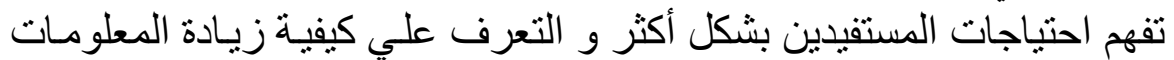

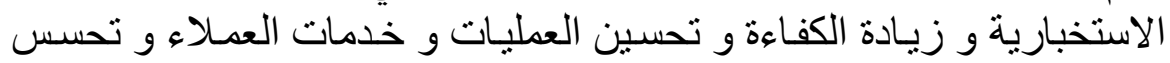

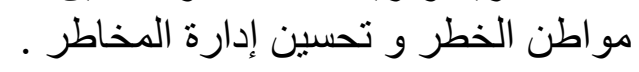

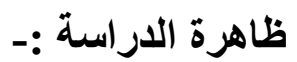

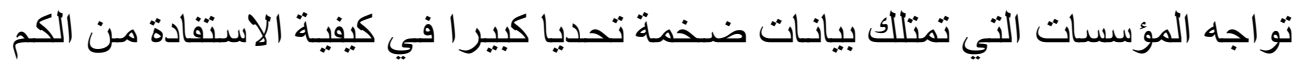

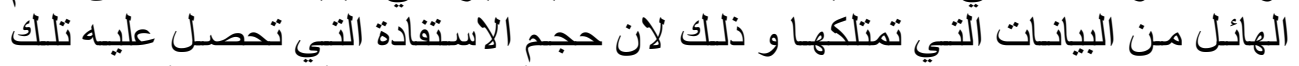

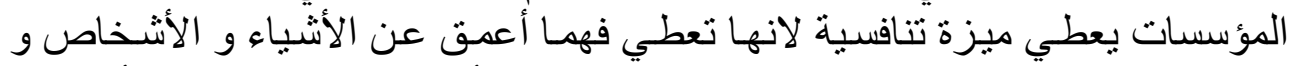

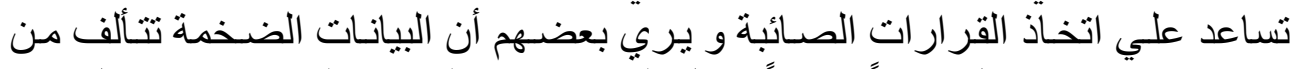

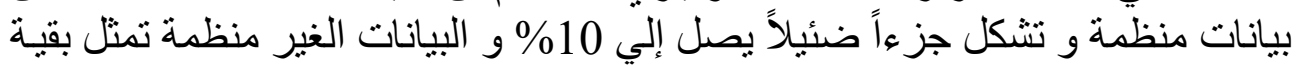
المحتوي.

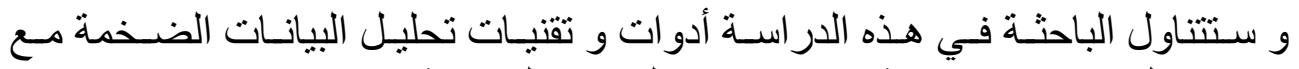

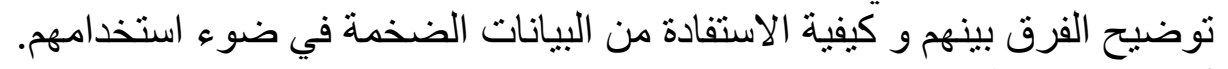
أهداف الاراسة: تهذف الدر اسة إلي مجمو عة من العناصر التالية:

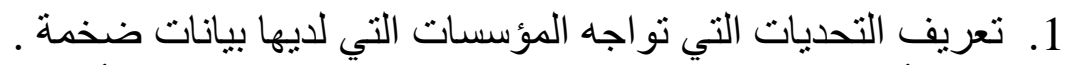

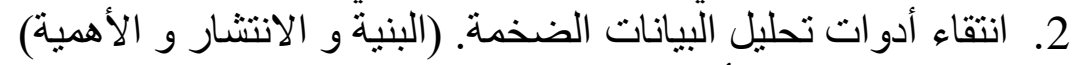

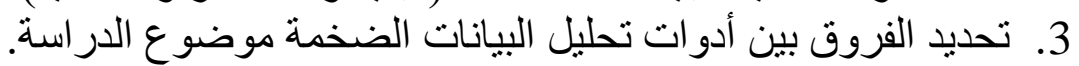

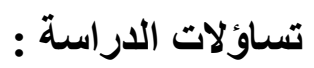

1. ما البيانات الضخمة مفهومهاو أنو اعهاو ومدي انتشار ها طرق الاستفادة منها؟

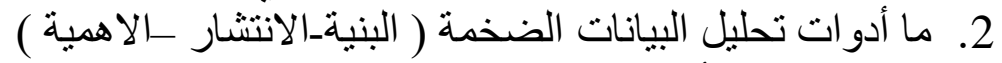

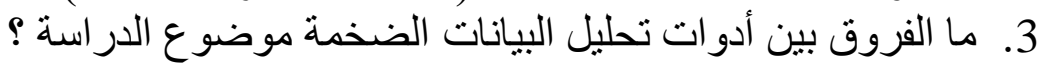

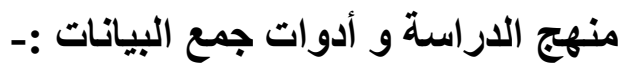

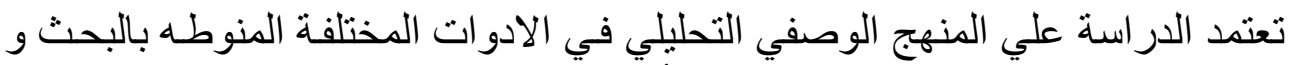

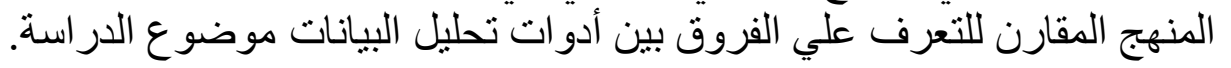
بداية نبدأ بالتعرف علي مصطلحات الدار اسة و التي علي منها:-

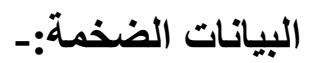
تعرف البيانات الضخمة بأنها مجمو عة من البيانات سواء غير مهيكلة و التي تتمثل في

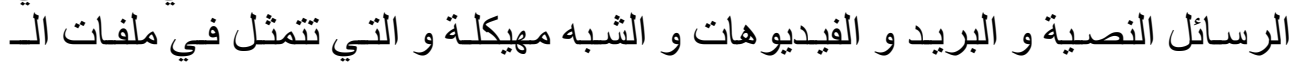

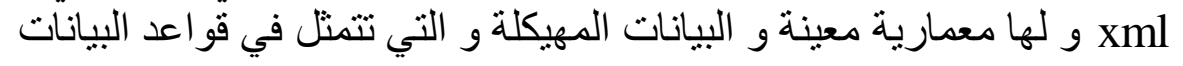
الهادوب وADOOP 
الثورة الصناعية الرابعة و أدواتها

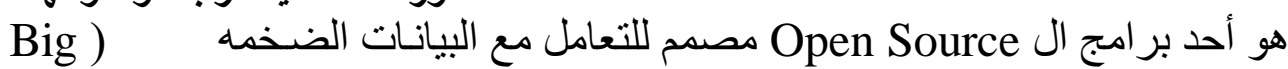
data إحصائيات لتبني عليها قرار ات لتهات

ساب هنا SAPHANA

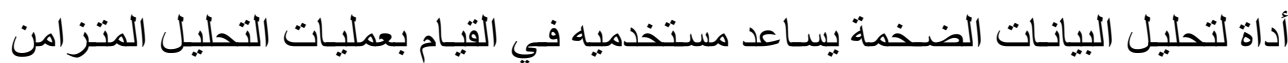
للبيانات الضخمة و التي ترد إلي منصة النظام مما يساعد علي سر عة اتخاذ القرار نو إس كيو إل NOSQL قو اعد بيانات تتيح تخزين و استرجاع البيانات بعد نمذجتها بتقنيات تختلف عن تلكات الكانك

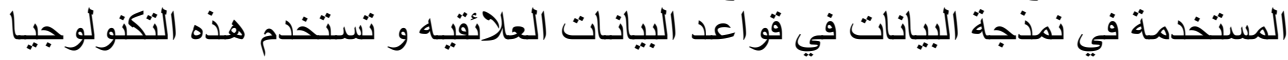

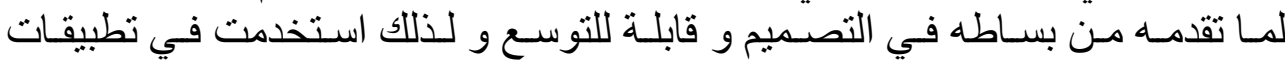

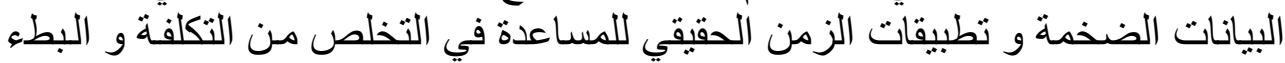
الثديد لقو اعد البيانات العلائقية

CLOUD COMPUTING الحوسبة السحابية

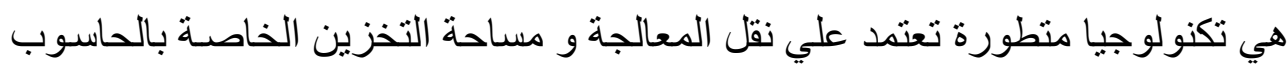

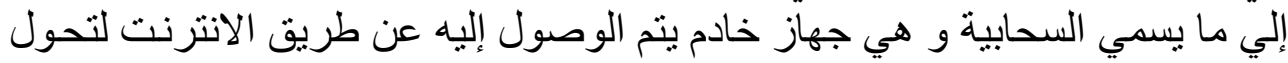

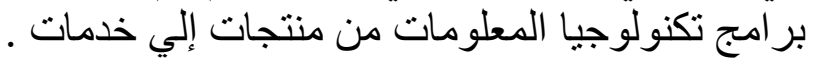

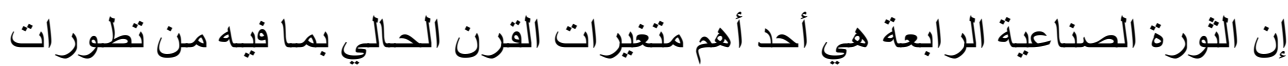

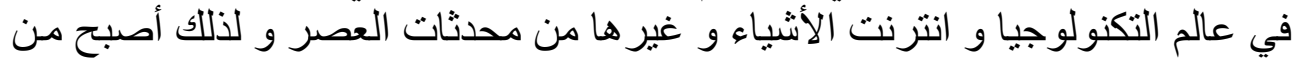


الضروري عقد مؤتمر ات و ندوات أند و كافة حلقات العلم و النقاش حول هذا المفهوم

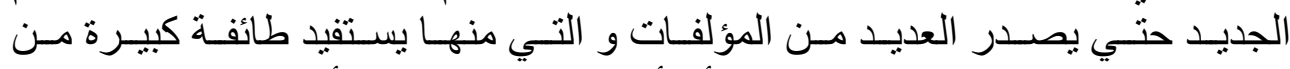

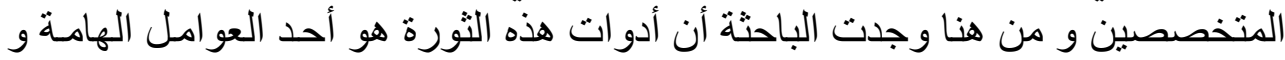

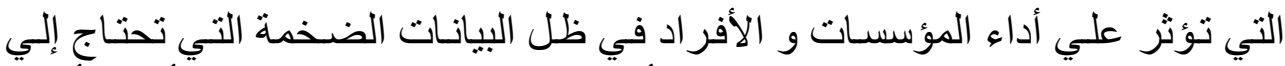

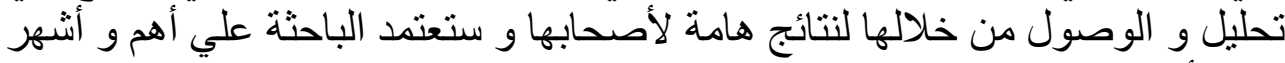

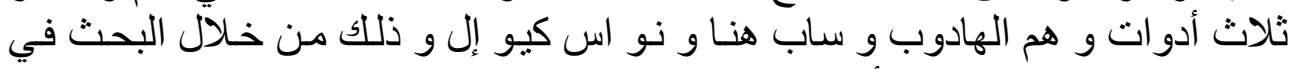
الإنتاج الفكري العربي و الأو الأجنبي.

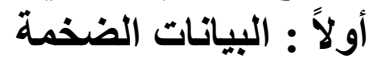

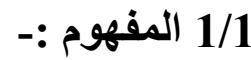

هي مجموعة من البيانات سو اء غير مهيكلة و التي تتمثل في الرسائل النصية و البريد

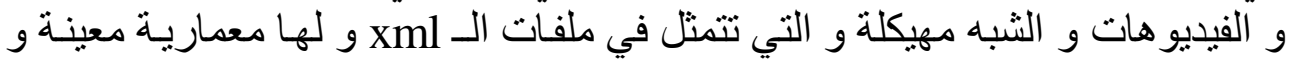

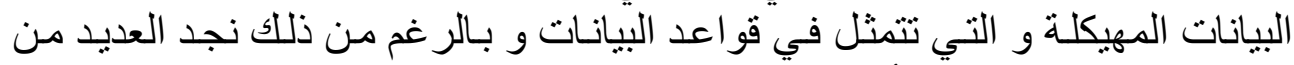

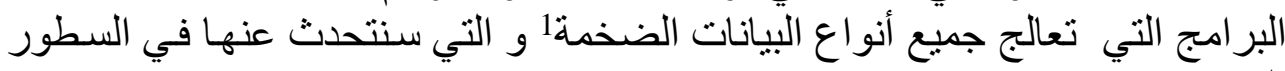

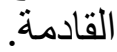
قبـل الحـديث عـن البرمجيـات المختلفـة المخصصــة لتحليـل البيانـات الضـخمة يجـب

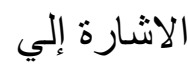

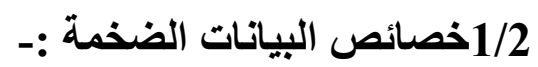

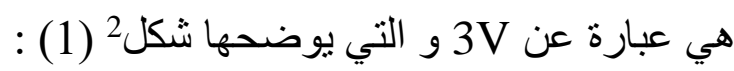

${ }^{1}$ Altahat,Khalid .suliman, taha.2018.moving towards the cloud.

المؤتمر الر ابع و العشرون :البيانات الضخمة و آفاق استثمار ها : الطريق نحو التكامل المعرفي.مسقط:جمعية

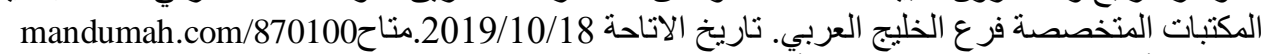
2 الأكلبي،على بن ديب.2015.أهمية تحليل البيانات الضخمة في التخاذية التخاذ القرار في جامعة الملك

ع 2019/10/18

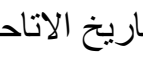

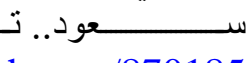
http://search.mandumah.com/870185 
الثورة الصناعية الرابعة و أدو اتها

VOLUME

- Terabytes

- Records

- Transactions

- Tables, files

\section{3 vs of}

Big Data

- Batch

- Near time

- Real time

- Structured

- Unstructured

- Semistructured

- Streams

- All the above

VELOCITY

\section{VARIETY}

$$
\begin{aligned}
& \text { شكل (1) خصائص البيانات الضخمة } \\
& \text { بالنظر إلي الشكل رقم (1) السابق نجد أن :- }
\end{aligned}
$$

بناء علي ما يعرضه الثكل السابق و هو معروض في شكل فن ثلاث كر ات متقاطعة

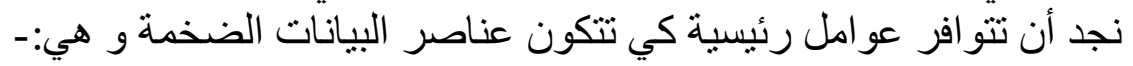

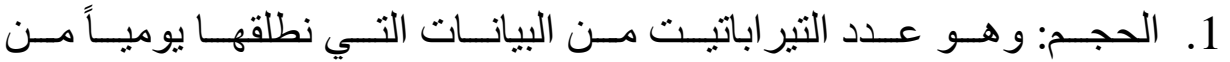

المحتوى.

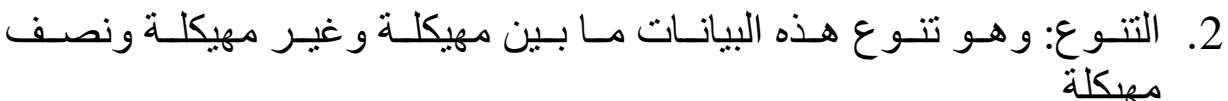

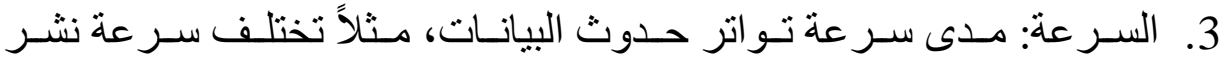

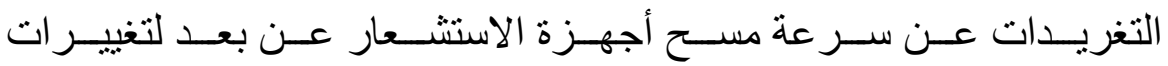

المناخ.

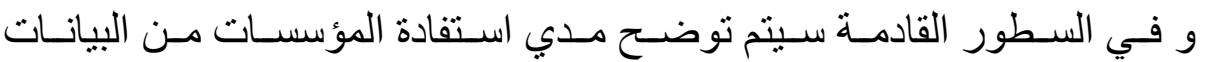

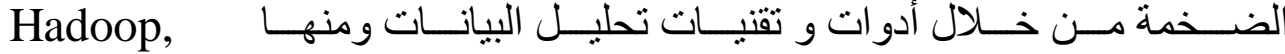

. saphana, nosql

HADOOP ثانياً: الهادوب

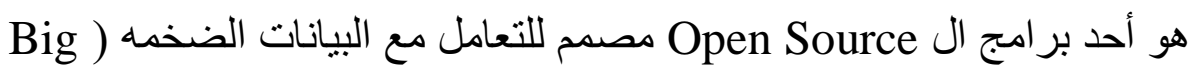
(data إحصائيات لتبني عليها قرار ات اتو 


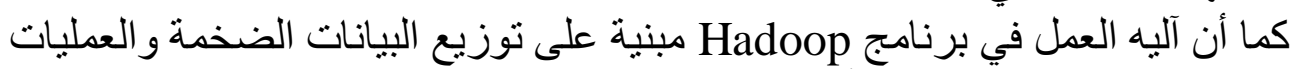

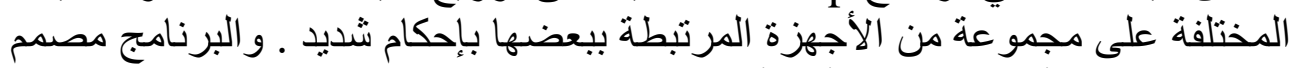

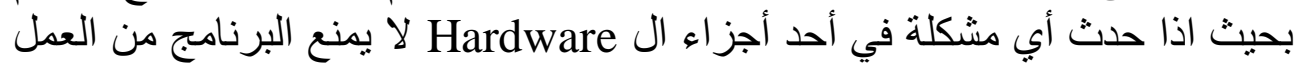

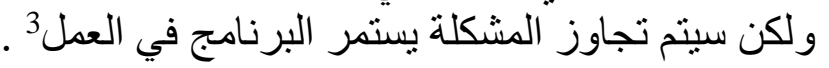

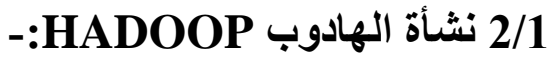

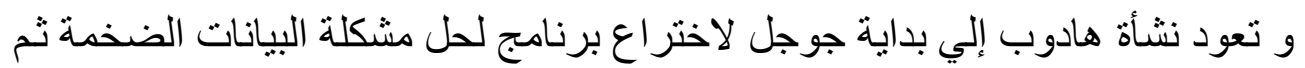

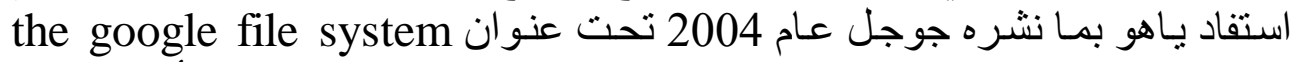

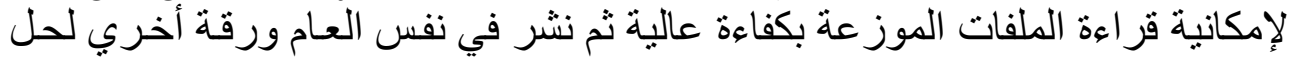

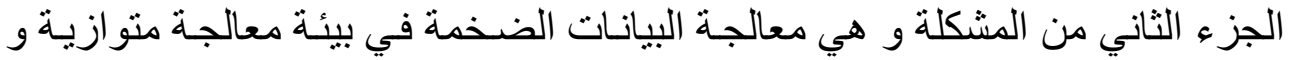

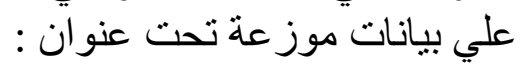

Mapreduce:simplified data processing on large clusters

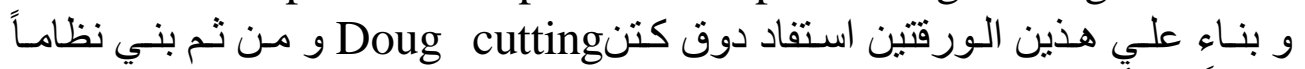

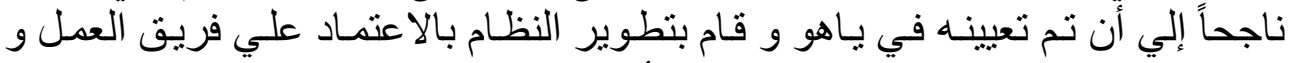

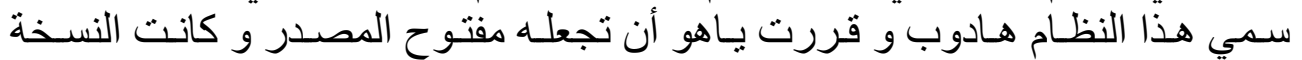

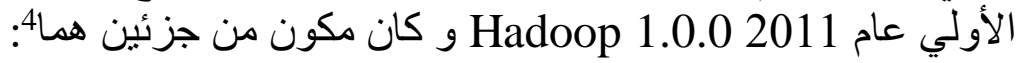

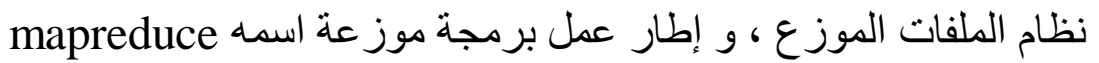

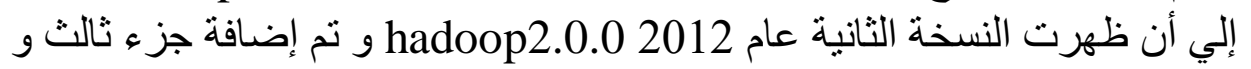
هو YARN ثم صدرت النسخة الكاملة عام 2017 hadoop3.0.0 إلي ان تو الت

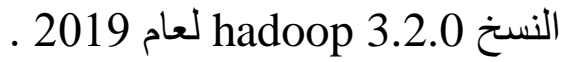

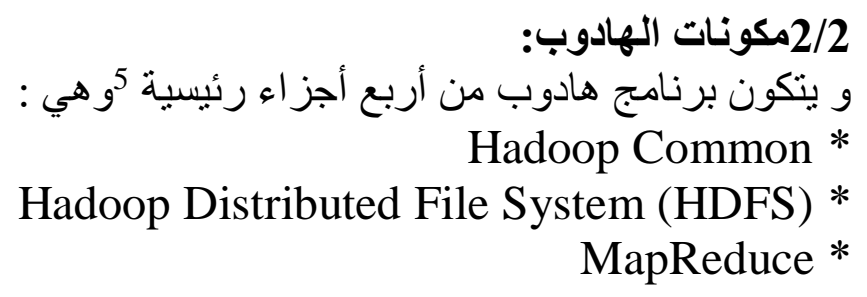

${ }^{3}$ Lakhe, bhushon.practical hadoop security:friends of apress.

4//: itwadi.com/Apache_Hadoop

${ }^{5}$ Leetaru,kalew h.2018.the user of future bigdata and remaginig how we

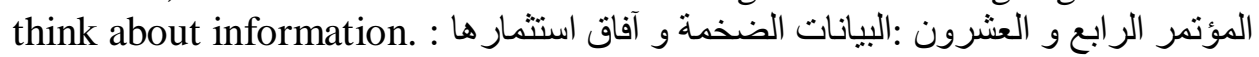

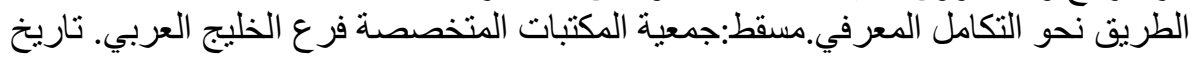

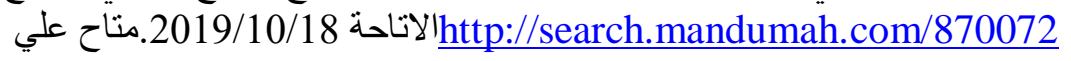


الثورة الصناعية الرابعة و أدواتها

Yet Another Resource Negotiator (YARN) * و نظر اً لأهية هذه الأجز اء فسوف نتناول وظيفة كل جز ع كالآتي:1

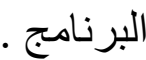
: بضع كل الداتا علي سيرفر ات ويقسم : Hadoop Distributed File System - 2

الداتا علي بلوكات و تتوزع علي النودز و اللي بتتقسم إلي Name Node, data

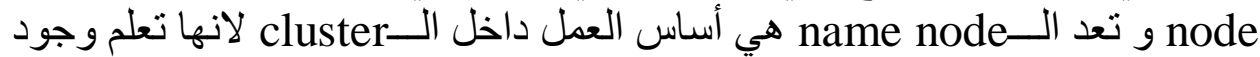

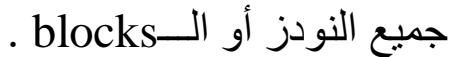
نو 3

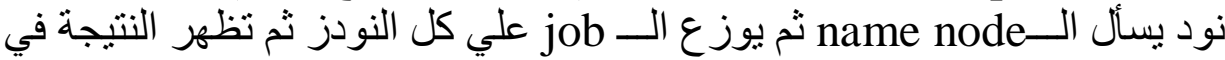

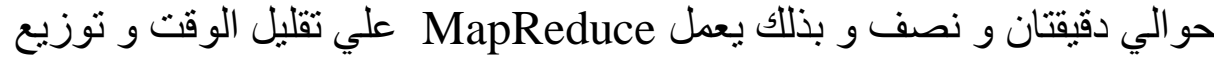

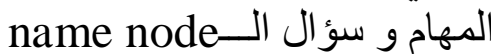

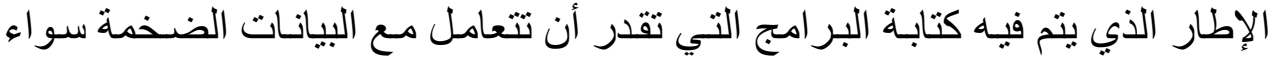

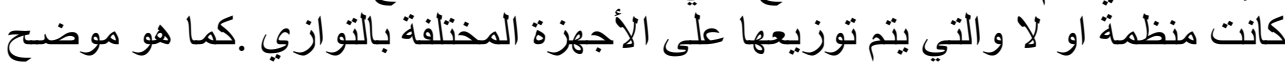

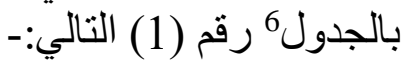

\begin{tabular}{|c|c|}
\hline اسم المهمة & Job Name \\
\hline الملف التنفيذي الرئيسي - هنا الفئة WordCount & Executable (Jar) Class \\
\hline الفئة التي تحتوي الدالة map وهي TokenizerMapper & Mapper Class \\
\hline الفئة التي تحتوي على الدالة reduce وهي IntSumReducer & Combiner \\
\hline الفئة التي تحتوي على الدالة reduce وهي IntSumReducer & Reducer \\
\hline نوع المخرج (المفتاح) وهو هنا Text & Output Key \\
\hline IntWritable نوع المخرج (القيمة) وهي هنا & Output Value \\
\hline تحديد مكان المدخل هنا Path(args[0] (سيتم تمرير المسار كمعطى للدالة main) & File Input Path \\
\hline تحديد مكان المخرج هنا (1] Path(args[1 (سيتم تمرير المسار كمعطى للدالة main) & File Output Path \\
\hline
\end{tabular}

Technology هي بلإدارة الأجهزة اللى بيتم توزيع البيانات : YARN - 4 خلالها وتعتبر الجيل القادم من ال Mapreduce

${ }^{6}$ Wadkar, Sameer,...etal.pro apache hadoop.friend of apress. 


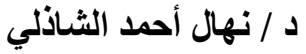

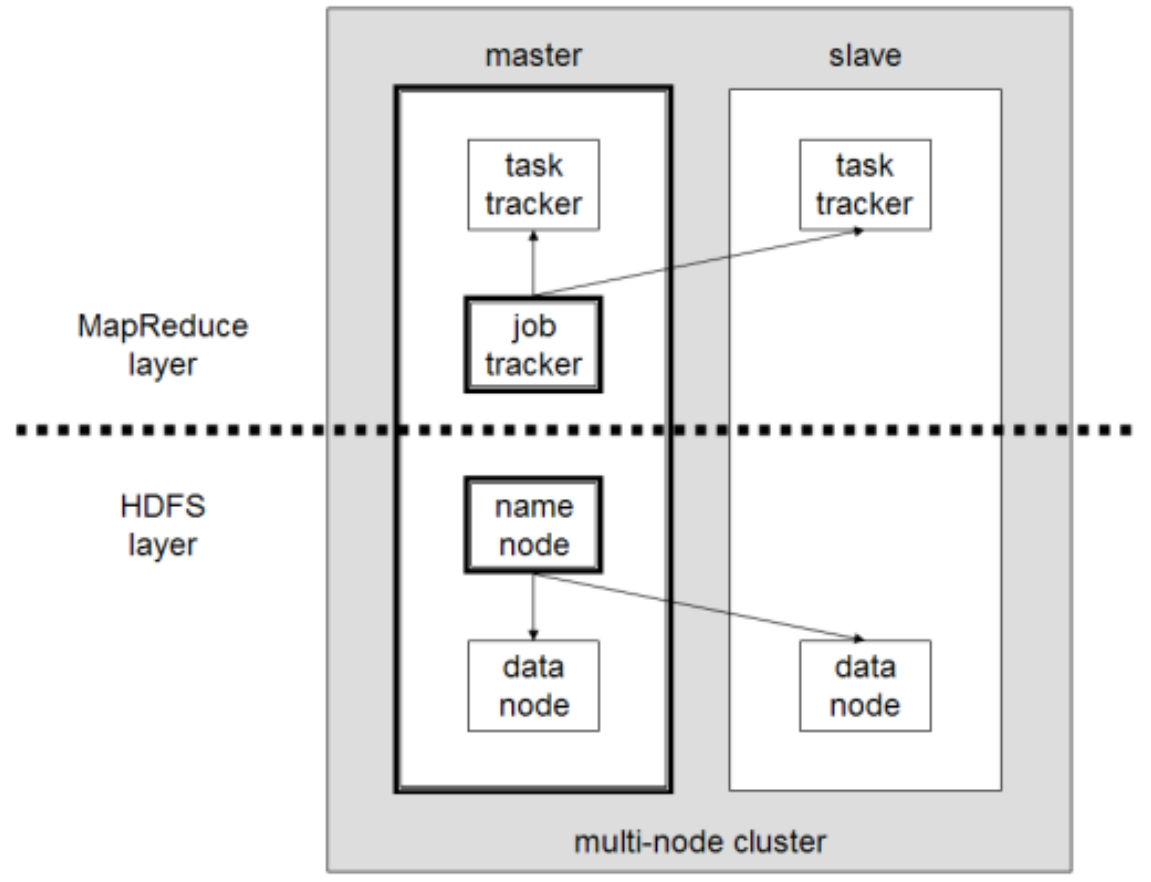

شكل(3) 7كيفية عمل الـهادوب

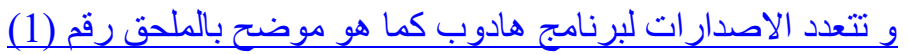
و الثكل ( 4 ) التالي يوضد الامح الفرق بين أول نسختين للنظام:-

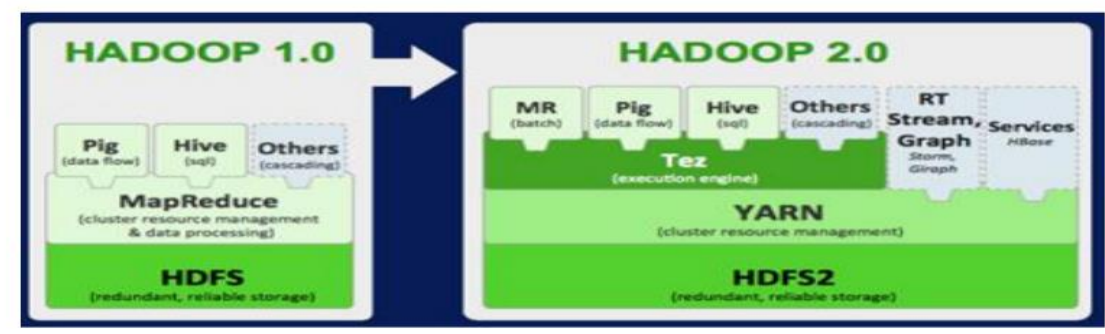

بالتعليق علي الثكل 4 السـابق يتضـح العديد من التعديلات و التطور ات علي نسـخة

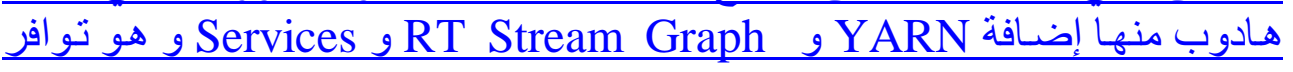

${ }^{7}$ https://

https://www.facebook.com/OpenitEG/photos/a.218684984974491.1073741 $828.202314549944868 / 463163927193261 /$ ?type $=1 \&$ theater 
الثورة الصناعية الرابعة و أدواتها

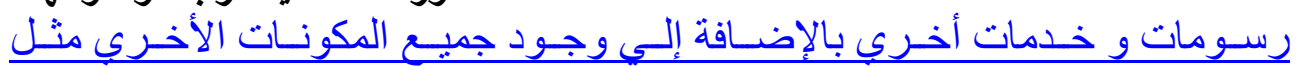

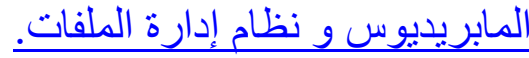

2/3 مميز ات الهادوب:

يتميز الهادوب بالخصائص التالية :-

ت 1

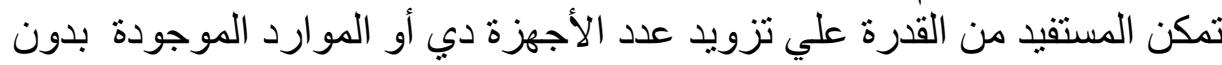

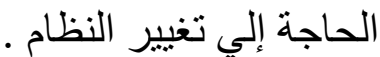

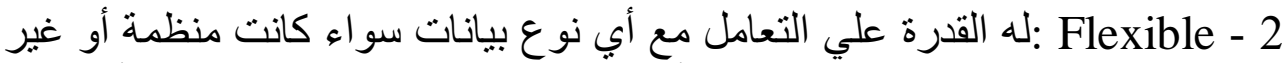

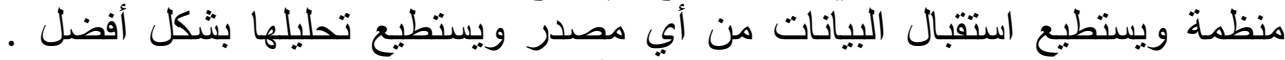
3 داخل البرنامج بتتم على التوازي لتحقيق أقصى استفادة ممكنه من المكونات وتقاتلاتليل التكلفة

4 - Fault tolerant - 4

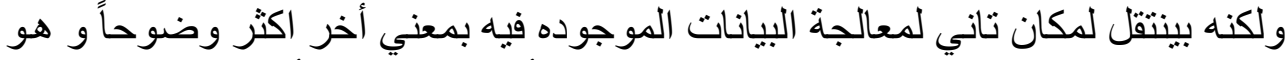

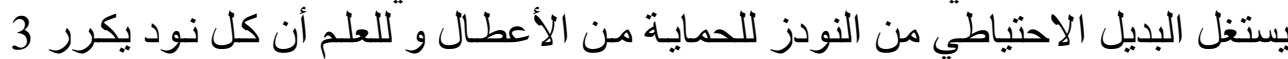

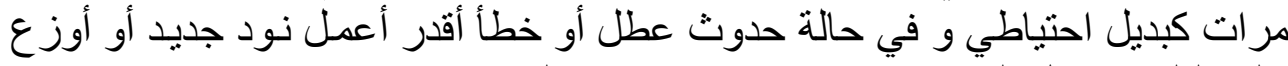

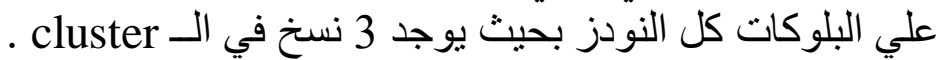

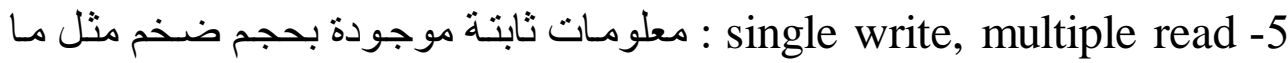
يوجد من بيانات في وكالة الفضاء ناسا و تقوم بمعالجة البيانات الثابتة و المستقرة .

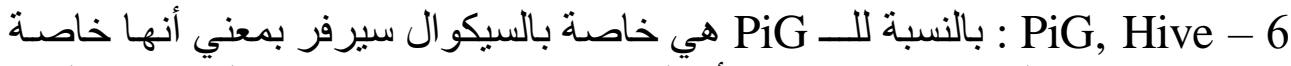

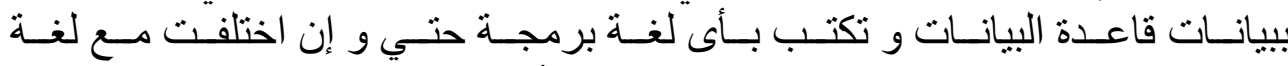

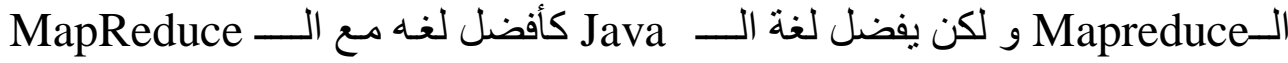

و بالنسبة للـ Hive عبارة عن Project جاهزة بتستخدم علثـان تنفذ مهام معينة و

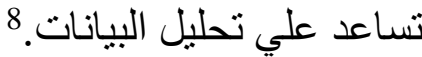
تإ:إنكانات الهادوب:تتمثل إمكانات الهادوب في السبعة عناصر التالية9 :-

\section{8/: itwadi.com/Apache Hadoop}

${ }^{9}$ https://www.sap.com/dam/application/shared/images/charts-diagrams/saphana-product-structure.png.adapt.800_-1.false.false.true.false.png 


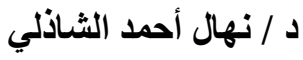 \\ 1. نمذجة المخاطر Risk Modeling \\ Customer churn Analysis .2 \\ Recommendation engine .3 \\ Ad targeting .4 \\ Transactional Analysis .5 \\ Threat analysis .6 \\ Search Quality .7}

\section{Sap Hana (in-memory) ثناتيا:ساب هانا}

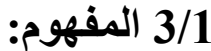

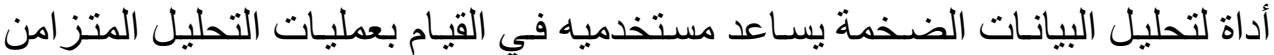

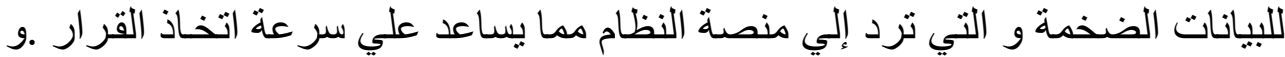

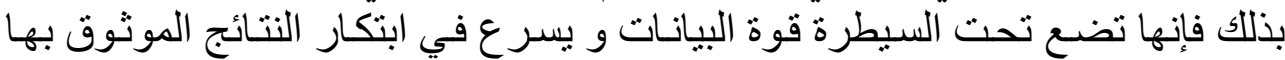

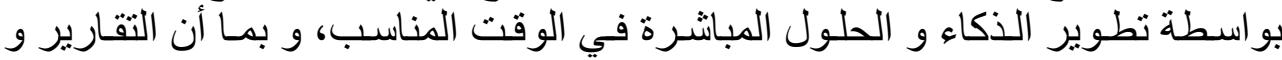

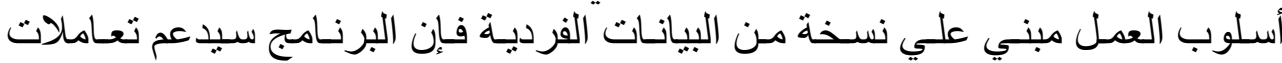

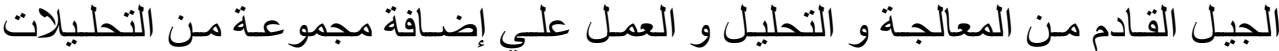

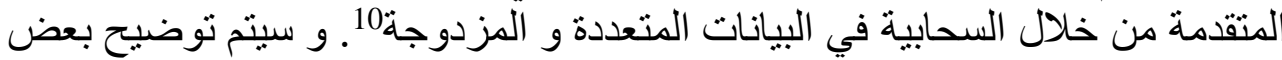

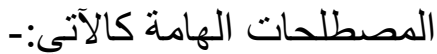
CLOUD SECURE Live

${ }^{10}$ Mira, Hasan .Sap hana (2019).available at :

https://www.youtube.com/watch?v=OFEwPwdIKW0 
الثورة الصناعية الرابعة و أدواتها

Broadest advanced analytics

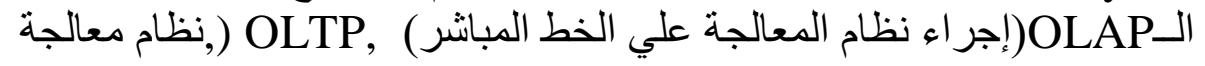

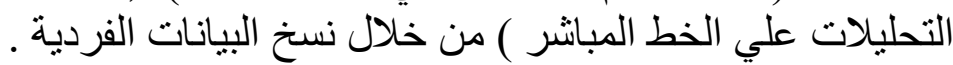

- 2/3 أجز اء الـــHANA

SAPHANA DB

• •

الاستديو و أي أدوات أخري ترسل كـ جهاز .

• • •

SAPHANA APPLICATION CLOUD

إلي البنية التحتية للقو اعد السحابية للتوصيل من الجهاز .

و الشكل (5) التالي يوضح مكونات و طريقة عمل البرنامج :-

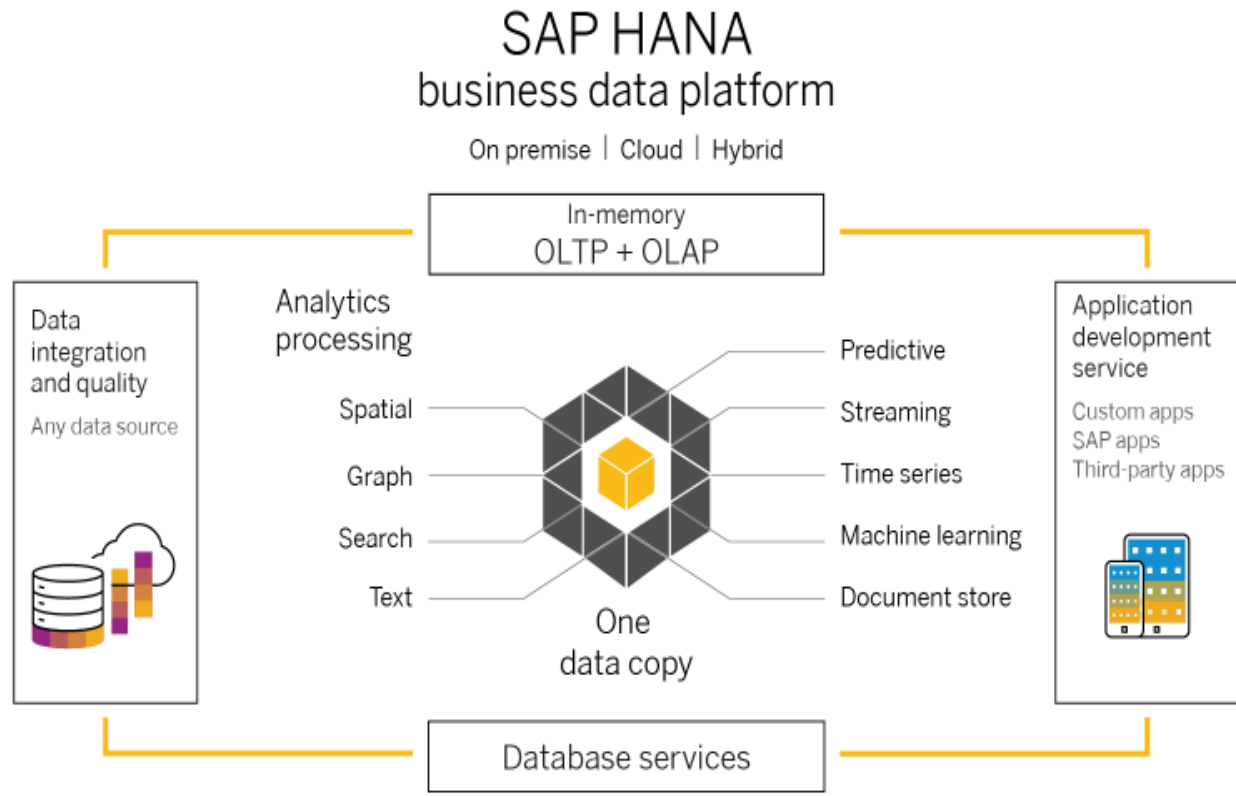

شكل (5) كيفية العمل برمجيات الـ Sap hana

${ }^{12}$ Sap hana (2019). available at:

11

https://www.youtube.com/watch?v=7RSSy7Azvr0 


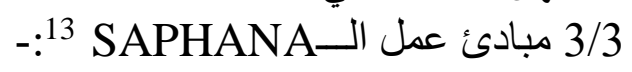

1. لأن لديها معالج و عدد كبير من الـRAM : In-memory computing بدل الهارد ديسك.

2. Column Based Storing : بـل الأعمـدة تسـتبدل بالملفـات لعمليـة ( الاسترجاع.

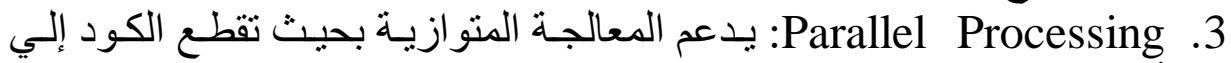
أجز اءو توز عها علي الـCPU المتعددة و بذلك تسر ع عملية المعالجة .

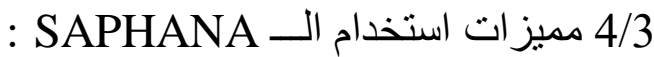

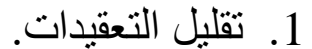

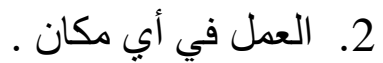

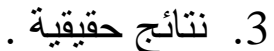

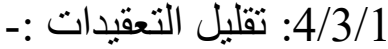

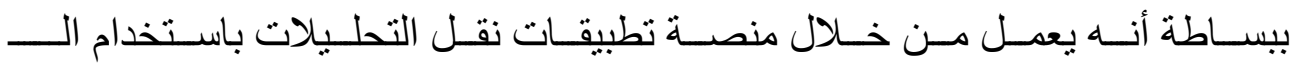

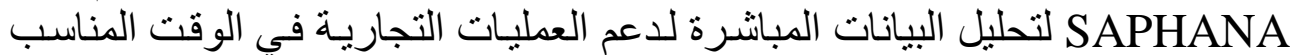

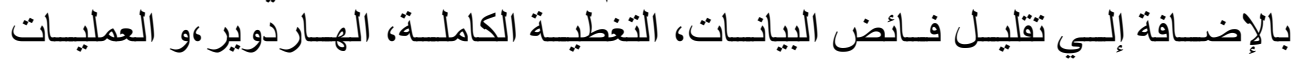
المستخدمة. - (الاضنة

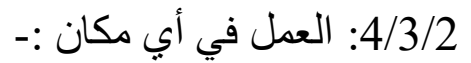

يفعل الوظائف سو اء بشكل عام أو بأ باستخدام تقنيات السحابية بشكل خاص ( مركز

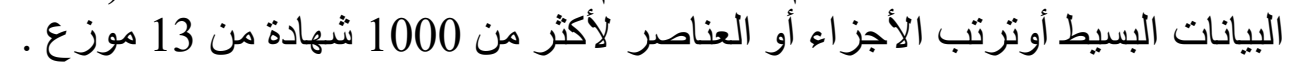

4/3/3 نتائج حقيقية :- الئن

الوصول إلي أفضل نتائج تجاريـة و زيادة نسبة الابتكار و تقليل تكلفة إدارة البيانات

${ }^{13}$ Saphana(2019). Available at :http://hana.sap.com/abouthana.html

${ }^{14}$ https://www.sap.com/dam/application/shared/images/charts-

diagrams/sap-hana-product-structure.png.adapt.800_-

1.false.false.true.false.png 
الثورة الصناعية الرابعة و أدو اتها

: Capabilities الامكانيات 5/3

: تغير إدارة قو اعد البيانات وذلك : Transform database management بيساطة يتم باستخدام العمليات من خلال نسخ فردية من مشرو عات البيانات و منصة حديثة لأمن البيانات .

:توفير السيولة المالية باستخدام التحليل Leverage advanced analytics

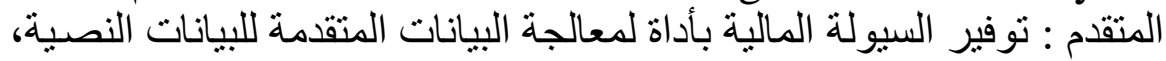
الصور الجر افيكية، و البيانات الهامة.

معالجـة البيانـات داخل الـذاكرة : معالجـة : Process data in-memory التعاملات و تحليل البيانات بالإضافة إلي وجود البيانات المستخدمة المتكاملـة المكررة داخل الذاكرة . ت التعات الاجئ Develop next generation applications الاجر اءات المزدوجة لتوفير السيولة المالية و القدرة علي معالجـة التحليلات لبناء تطبيقات الجيل القادمات 15

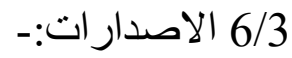

\begin{tabular}{|c|c|c|c|c|}
\hline $\begin{array}{l}\text { Saphana } \\
\text { runtime } \\
\text { edition }\end{array}$ & $\begin{array}{r}\text { Saphana } \\
\text { express } \\
\text { edition }\end{array}$ & $\begin{array}{r}\text { Saphana } \\
\text { standard } \\
\text { edition }\end{array}$ & $\begin{array}{r}\text { Saphana } \\
\text { enterprise } \\
\text { edition }\end{array}$ & وجه المقارنة \\
\hline & & & & 1-database service \\
\hline$\sqrt{ }$ & $\sqrt{ }$ & $\sqrt{ }$ & $\sqrt{ } 1$ & -Columnar oltp\&olap \\
\hline$\sqrt{ }$ & $\sqrt{ }$ & $\sqrt{ }$ & $\sqrt{ }$ & -columnar RDBMS \\
\hline$\sqrt{ }$ & $\sqrt{ }$ & $\sqrt{ }$ & $\sqrt{ }$ & $\begin{array}{l}\text {-online analytical } \\
\text { processing (olap) }\end{array}$ \\
\hline$\sqrt{ }$ & $\sqrt{ }$ & $\sqrt{ }$ & $\sqrt{ }$ & $\begin{array}{l}\text {-online } \\
\text { transactional } \\
\text { processing } \\
\text { (oltp) }\end{array}$ \\
\hline$\sqrt{ }$ & $\sqrt{ }$ & $\sqrt{ }$ & $\sqrt{ }$ & $\begin{array}{l}\text {-multicore and } \\
\text { parallelization }\end{array}$ \\
\hline$\sqrt{ }$ & $\sqrt{ }$ & $\sqrt{ }$ & $\sqrt{ }$ & -advanced \\
\hline
\end{tabular}

${ }^{16}$ https://www.sap.com/mena/products/hana.html

$$
15
$$




\begin{tabular}{|c|c|c|c|c|}
\hline $\begin{array}{l}\text { Saphana } \\
\text { runtime } \\
\text { edition }\end{array}$ & $\begin{array}{r}\text { Saphana } \\
\text { express } \\
\text { edition }\end{array}$ & $\begin{array}{r}\text { Saphana } \\
\text { standard } \\
\text { edition }\end{array}$ & $\begin{array}{r}\text { Saphana } \\
\text { enterprise } \\
\text { edition }\end{array}$ & وجه المقارنة \\
\hline & & & & compression \\
\hline$\sqrt{ }$ & $\sqrt{ }$ & $\sqrt{ }$ & $\sqrt{ }$ & \\
\hline$\sqrt{ }$ & $\sqrt{ }$ & $\sqrt{ }$ & $\sqrt{ }$ & -multitenancy \\
\hline $3 \sqrt{ } \sqrt{ }$ & -2 & $\sqrt{ }$ & $\sqrt{ }$ & -multitier storage \\
\hline$\sqrt{ } \sqrt{ }$ & $\sqrt{ }$ & $\sqrt{ }$ & $\sqrt{ }$ & -data modeling \\
\hline$\sqrt{ } \sqrt{ }$ & $\sqrt{ }$ & $\sqrt{ }$ & $\sqrt{ }$ & $\begin{array}{l}\text {-openness } \\
\text { (standard interface) }\end{array}$ \\
\hline$\sqrt{ }$ & $\sqrt{ }$ & $\sqrt{ }$ & $\sqrt{ }$ & $\begin{array}{l}\text {-administration and } \\
\text { security }\end{array}$ \\
\hline \multirow[t]{2}{*}{$\sqrt{ }$} & - & $\sqrt{ }$ & $\sqrt{ }$ & $\begin{array}{l}\text {-high availability and } \\
\text { disaster recovery }\end{array}$ \\
\hline & & & & 2- application services \\
\hline$\sqrt{ } \sqrt{ }$ & $\sqrt{ }$ & $\sqrt{ }$ & $\sqrt{ }$ & -webserver \\
\hline$\sqrt{\sqrt{ }}$ & $\sqrt{ }$ & $\sqrt{ }$ & $\sqrt{ }$ & -Java script \\
\hline$\sqrt{ } \sqrt{ }$ & $\sqrt{ }$ & $\sqrt{ }$ & $\sqrt{ }$ & -sap fioriux \\
\hline$\sqrt{ }$ & $\sqrt{ }$ & $\sqrt{ }$ & $\sqrt{ }$ & -graphic modeler \\
\hline \multirow[t]{2}{*}{$\sqrt{ } \sqrt{ }$} & $\sqrt{ }$ & $\sqrt{ }$ & $\sqrt{ }$ & $\begin{array}{l}\text {-application lifecycle } \\
\text { management }\end{array}$ \\
\hline & & & & 3-processing services \\
\hline$\sqrt{ } \sqrt{ }$ & $\sqrt{ }$ & ${ }^{4} 0$ & $\sqrt{ }$ & -spatial \\
\hline$\sqrt{ } \sqrt{ }$ & $\sqrt{ }$ & 0 & $\sqrt{ }$ & -graph \\
\hline$\sqrt{ } \sqrt{ }$ & $\sqrt{ }$ & 0 & $\sqrt{ }$ & -predictive \\
\hline$\sqrt{ } \sqrt{ }$ & $\sqrt{ }$ & 0 & $\sqrt{ }$ & -search \\
\hline$\sqrt{ } \sqrt{ }$ & $\sqrt{ }$ & 0 & $\sqrt{ }$ & -text analytics \\
\hline- & $\sqrt{ }$ & 0 & $\sqrt{ }$ & -streaming analytics \\
\hline$\sqrt{ } \sqrt{ }$ & $\sqrt{ }$ & $\sqrt{ }$ & $\sqrt{ }$ & -series data \\
\hline \multirow[t]{2}{*}{$\sqrt{ } \sqrt{ }$} & $\sqrt{ }$ & $\sqrt{ }$ & $\sqrt{ }$ & -business functions \\
\hline & & & & $\begin{array}{l}\text { 4- integration and } \\
\text { quality services }\end{array}$ \\
\hline$\sqrt{ } \sqrt{ }$ & $\sqrt{ }$ & $\sqrt{ }$ & $\sqrt{ }$ & -data virtualization \\
\hline$\sqrt{ } \sqrt{ }$ & - & 0 & $\sqrt{ }$ & -etland replication \\
\hline$\sqrt{ } \sqrt{ }$ & - & 0 & $\sqrt{ }$ & -data quality \\
\hline
\end{tabular}




\begin{tabular}{|c|c|c|c|c|}
\hline $\begin{array}{l}\text { Saphana } \\
\text { runtime } \\
\text { edition }\end{array}$ & $\begin{array}{r}\text { Saphana } \\
\text { express } \\
\text { edition }\end{array}$ & $\begin{array}{r}\text { Saphana } \\
\text { standard } \\
\text { edition }\end{array}$ & $\begin{array}{r}\text { Saphana } \\
\text { enterprise } \\
\text { edition }\end{array}$ & وجه المقارنة \\
\hline$\sqrt{ } \sqrt{ }$ & $\sqrt{ }$ & 0 & $\sqrt{ }$ & $\begin{array}{l}\text {-hadoop and spart } \\
\text { integration }\end{array}$ \\
\hline- & $\sqrt{ }$ & 0 & $\sqrt{ }$ & -remote data synch \\
\hline
\end{tabular}

$$
\text { نستتنج من الجدول رقم (2) السابق ما يلي:- }
$$

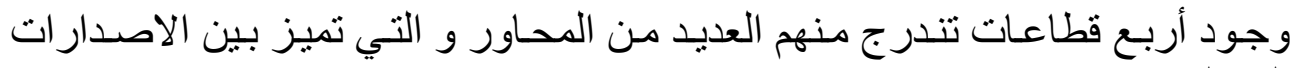

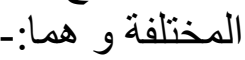

$$
\begin{aligned}
& \text { - خدمات قاعدة البيانات. } \\
& \text { - خدمات التطبيقات. } \\
& \text { - خدمات المعالجة . } \\
& \text { - التكامل و جودة الخدمة. }
\end{aligned}
$$

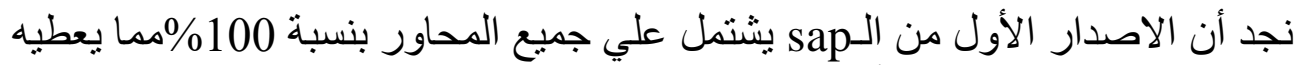

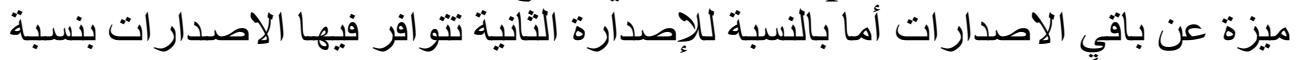
100\% أيضاً و لكن مع وجود 10 محساور بشكل اختياري و نجد أن الاصدي الاصدار الثالث

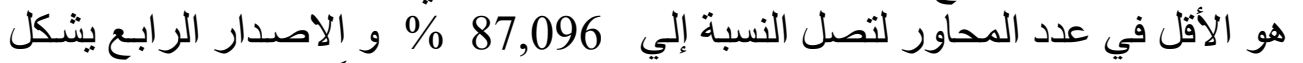

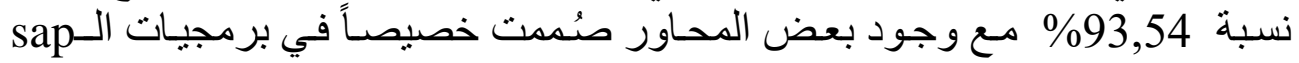

رابعاً: تكنولوجيا NOSQL (NOT ONLY SQL )

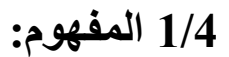

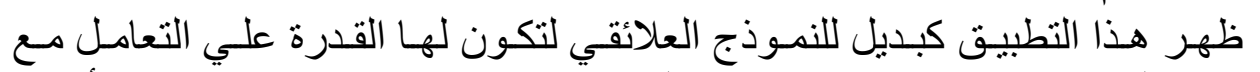

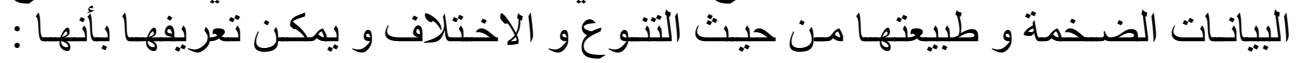

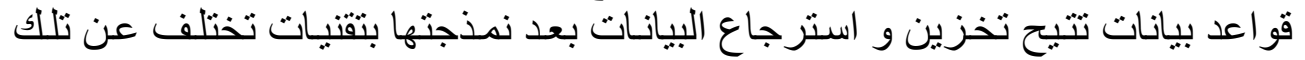

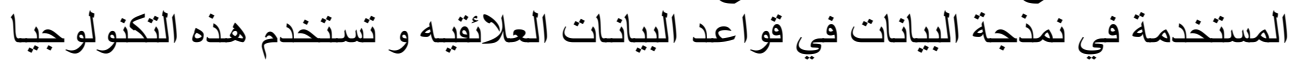

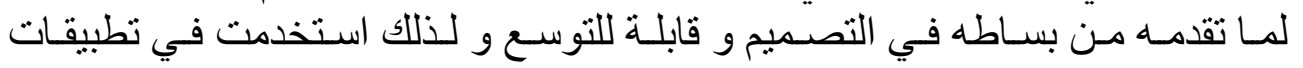

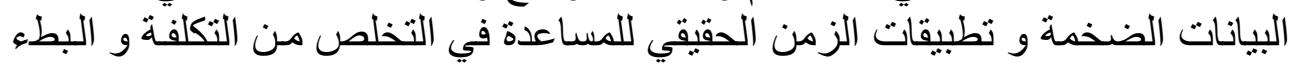

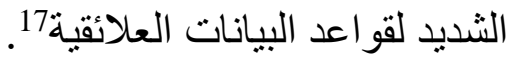

${ }^{17}$ A Comparison Of NoSQL Database Management Systems And Models(2019) available 


\begin{tabular}{|c|c|c|}
\hline NOSQL & SQL & أوجه المقارنة \\
\hline $\begin{array}{l}\text { تسمح بعمليات انسياب حر } \\
\text { free- } \\
\text { flaw }) \\
\text { (operation }\end{array}$ & تلتي البيانات هيكلــة ذات خصــائص محـددة للحفـاذ & 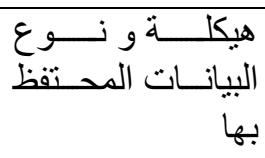 \\
\hline 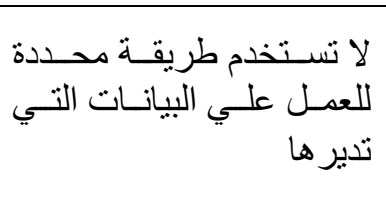 & 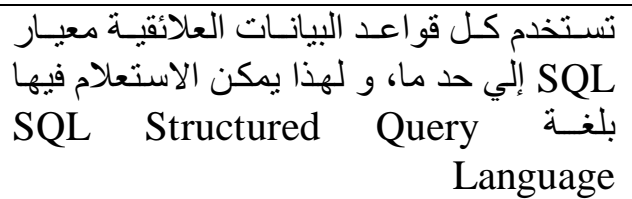 & الاستعلام \\
\hline 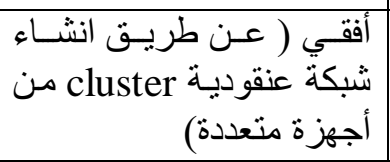 & عمودي ( أي بزيادة موارد النظام) & 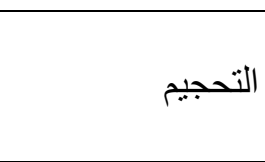 \\
\hline 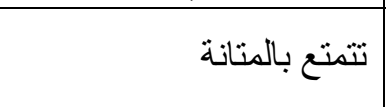 & تتمنع بمتانة أفضل من أي قاعدة بيانات & \\
\hline \multicolumn{3}{|c|}{ 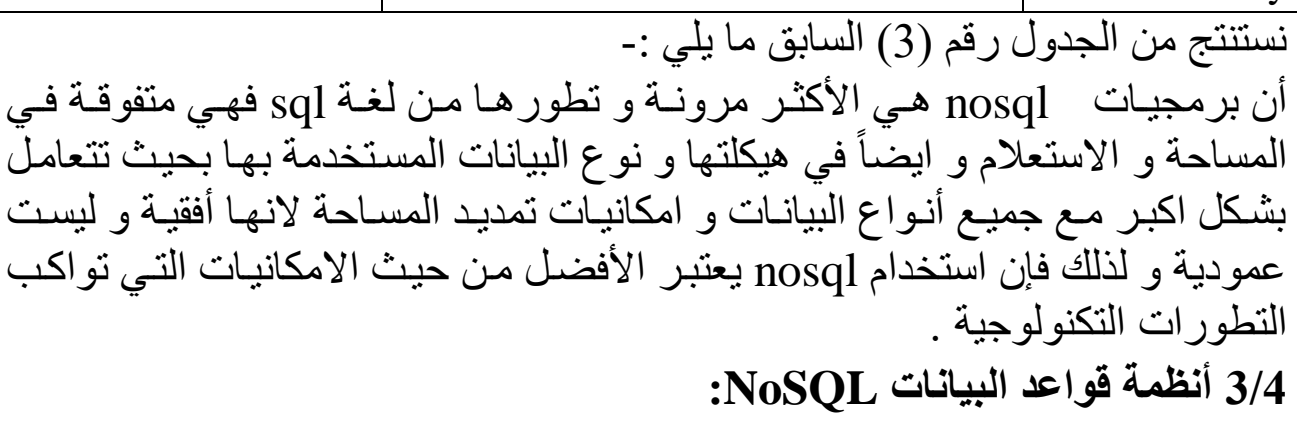 } \\
\hline
\end{tabular}

\section{Key-Value stores .1}

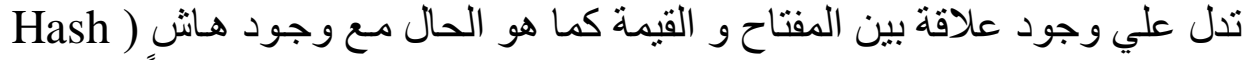

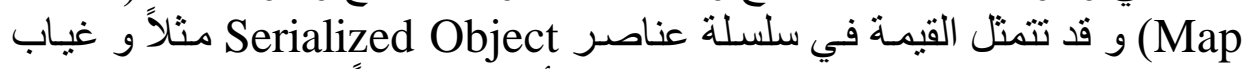

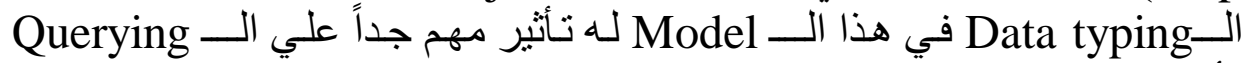
لأن التو اصل مع قاعدة البيانات سيقتصر علي ثلاث عمليات فقط : Delete, put,

Get

at:https://www.digitalocean.com/community/tutorials/a-comparison-ofnosql-database-management-systems-and-models 
الثورة الصناعية الرابعة و أدو اتها

Column Oriented .2

يتشابه بشكل كبير مع RDBMS إلا أن عدد أعمدته ديناميكي علي عكس الجداول

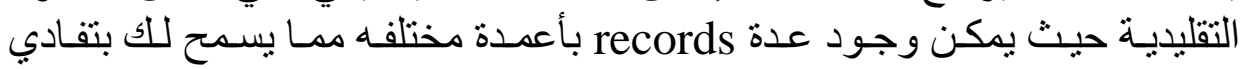
وضع Null في الخانات الز ائدة.

Document-based .3

يعتمد هذا الـModel عey-Values علي نموذج القيمة في هذه الحالة هي ملف

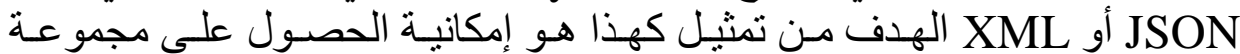

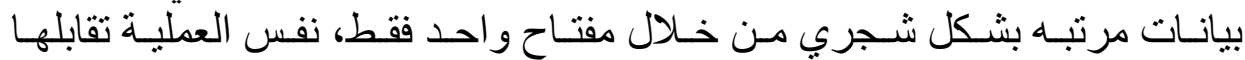

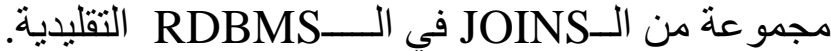

Graph Data Model .4

يعتمد هذا الــ Model علي الــ Graph Theory حيث تحنوي كل عقده (علي

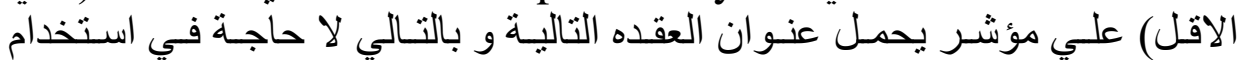

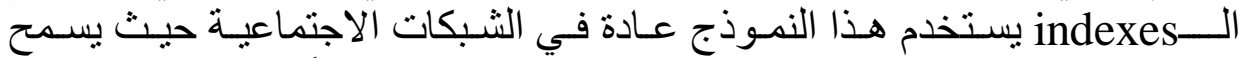

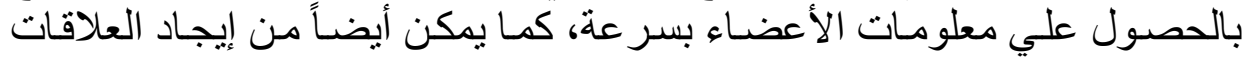

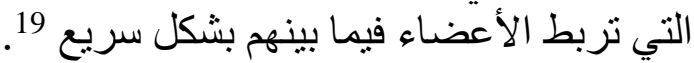

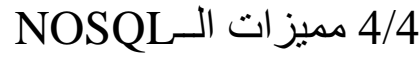

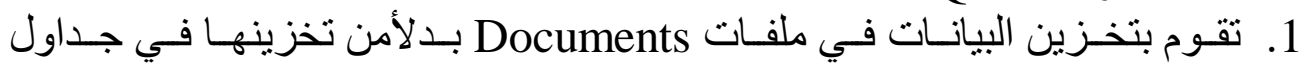
.Tables

2.

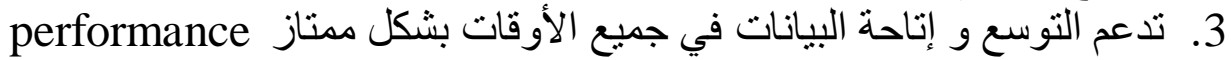
. ${ }^{20}$ and availability خامساً:أنظمة أخري لإدارة البيانات الضخمة21 : :Mongo DB .1

${ }^{19}$ Corbellini, alejandro2017.persisting big-data:the nosql

landscape.date18/12/2018 availanle at : www.elsevier.com/locate/Infosys

${ }^{20}$ Biceuska, zane.oditis,Ivo.2017.towards nosql-based data warehouse solutions date27/07/2018.available at :

http://creativecommons.org/licenses/by-nc-nd/4-01

${ }^{21}$ Chandra, dekaganesh.2015.base analysis of nosql database.date18/12/2018available at : http://www.elsevier.com/locate/f9cs 
د د / نهال أحمد الشاذلي

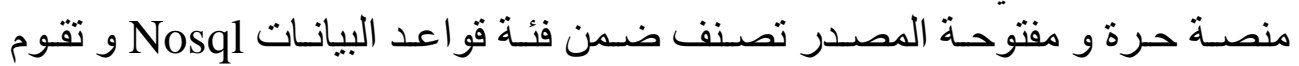

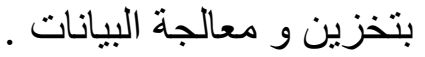

: Cassandra .2

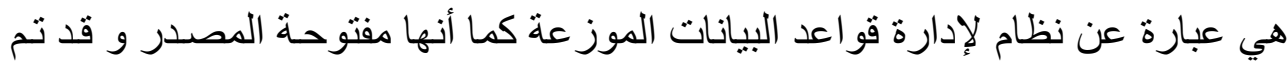

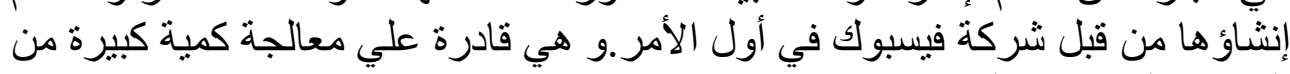

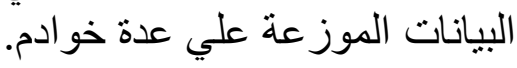
: Spark .3

هي واحدة من أكثر مشـاريع Apache نشـاطاً و هي منصـة حوسبة عنقوديـة مفتوحة المصدر.

: Google Fusion Tables .4

منصة ذات إمكانيات كبيرة في تحليل البيانات و تجسيدها علي شكل رسوم بيانية و

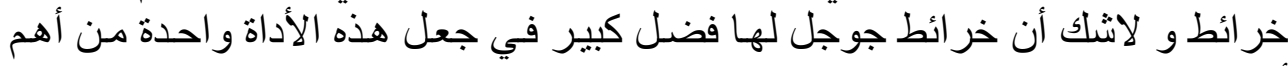
أدوات تحليل البيانات. : Node XL .5

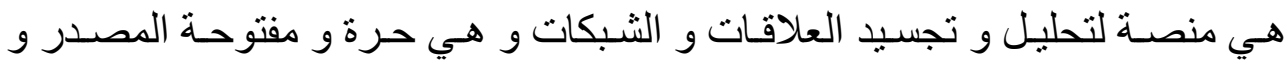

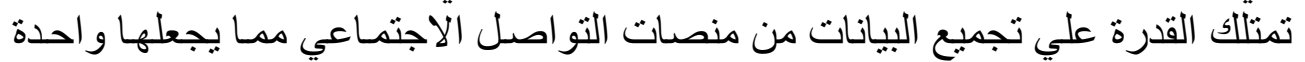

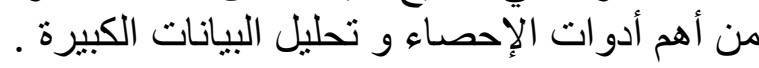
:Couch DB .6

قاعدة بيانات مفتوحة المصدر من فئسة Nosql قادرة علي تخزين و معالجـة البيانـات الضخمة في صيغة Json : Apache Hive .7 واحدة من أفضل منصات تحليل البيانات الضخمة. : Tableau .8

هي أداة مجانيـة تمكن مـن التأكد مـن صـحة الفرضيات و استكثـاف البيانـات بشكل : Rapid Miner .9 سريع .

هي منصـة تحليل البيانـات مفتوحة المصدـر تسـاعد علـي تمثيـل البيانـات و معالجتهـا

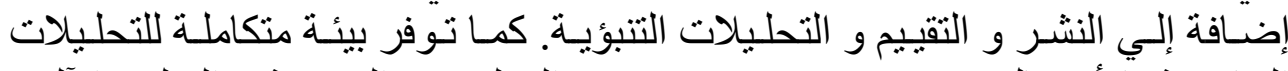
الخاصـة بألأعمـال business analytics و التحلـيلات التنبؤيسة و التعلـيم الآلكي

. Machine learning

: Open Refine .10 
الثورة الصناعية الرابعة و أدواتها

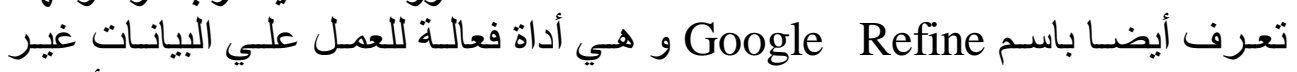

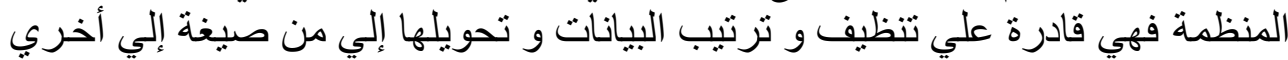

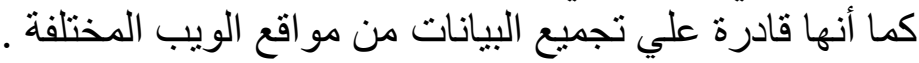

: Knime .11

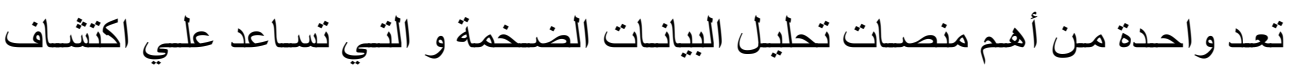

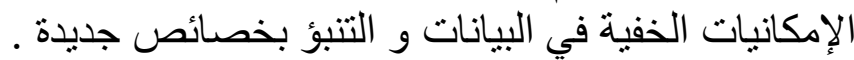

: Wolfram Alpha 12

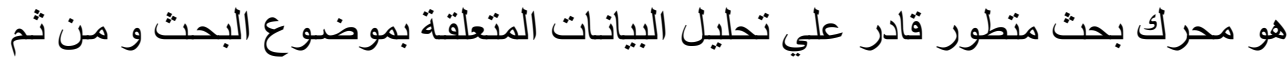

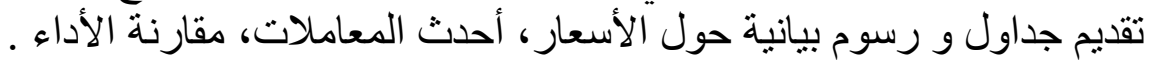

: Solver .13

هي أداة مضافة علي برنامج Microsoft office excel إنها أداة معالجـة متقدمة

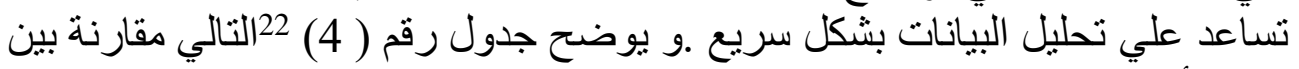
بعض أدو ات تحليل البيانات الضخمة :-

\begin{tabular}{|c|c|c|}
\hline مواطن الضعف & الامكانيات & الأداة//المنصة \\
\hline ـ اكسيل أو TXTل بيانـات سـوي فـي صـورة & 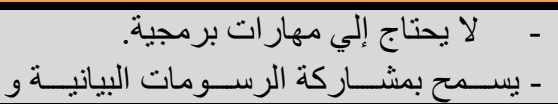 & $\begin{array}{r}\text { Tableau } \\
\text { Public }\end{array}$ \\
\hline
\end{tabular}

${ }^{22}$ Hamad , $\mathrm{f}(\ldots$. etal).2018.bigdataand analytics strategies in academic libraries:opportunities and challenges, the case of the university of Jordon library. المؤتمر الرابع و العشرون :البيانات الضخمة و آفاق استثمار ها : الطريق نحو التكامل المعرفي.مسقط:جمعية المكتبات المتخصصة فرع الخليج العربي. تاريخ الاتاحة 2019/10/18http://search.mandumah.com/870281 


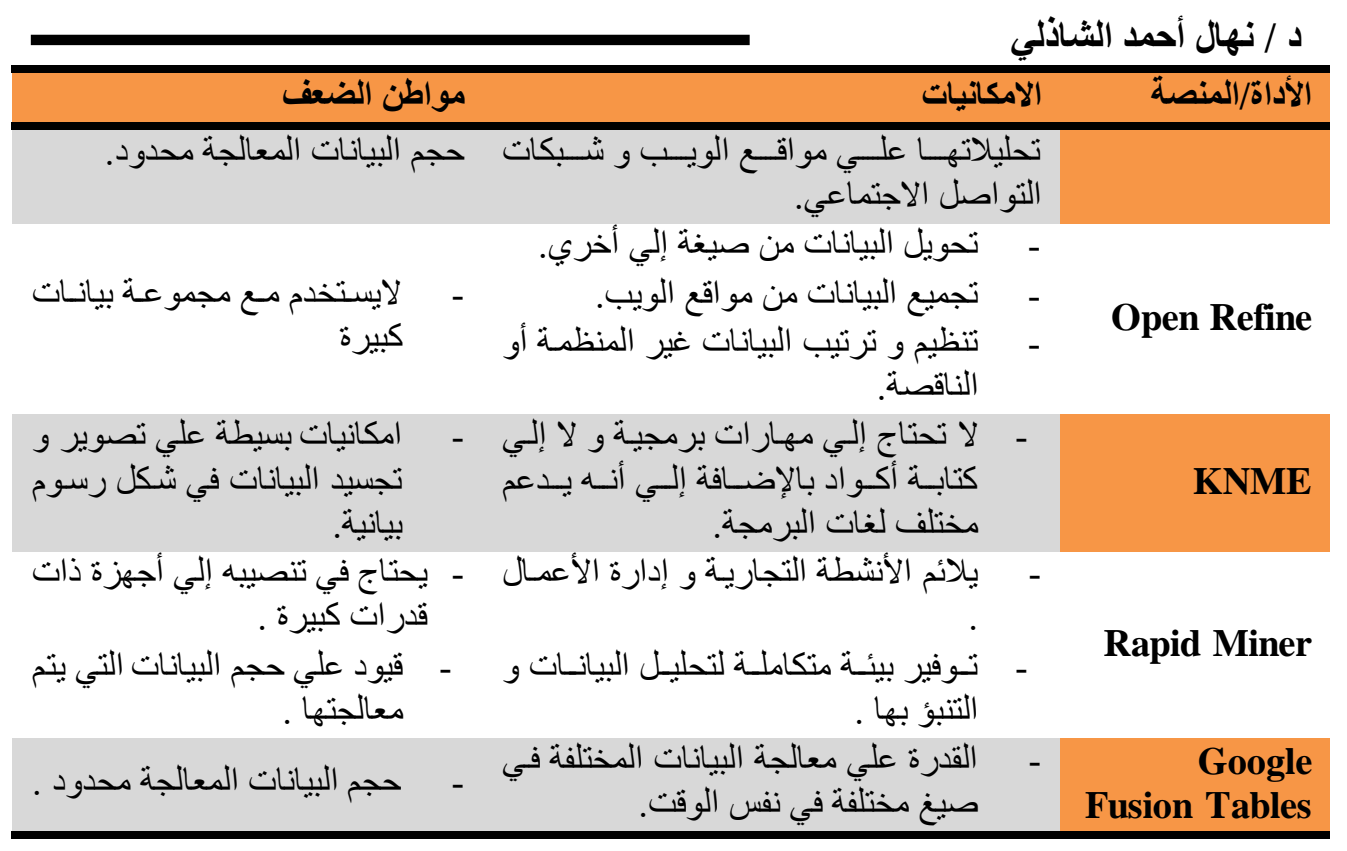

يتبين مـن الجدول ( 4 ) السـابق أن أغلب أدوات تحليل البيانـات محدودة في عملية

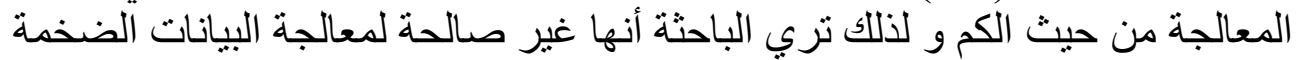

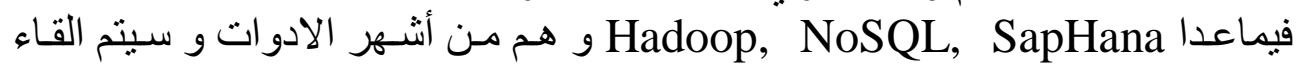

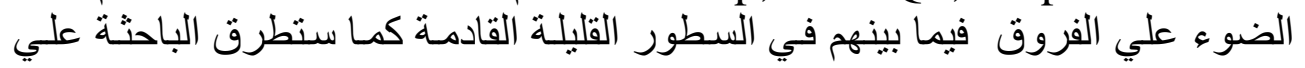

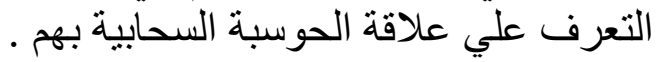

\section{سادساً الحوسبة السحابية : 1/6تعريف الحوسبة :}

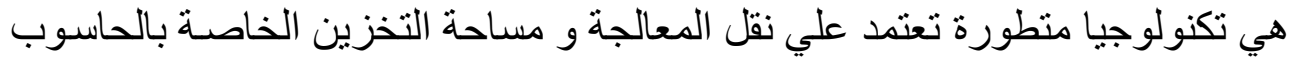

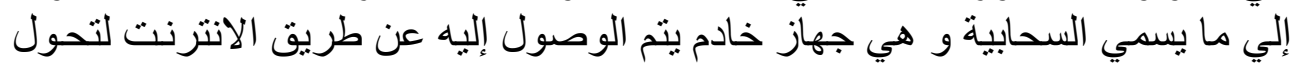

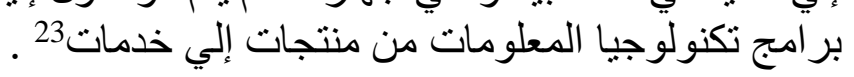

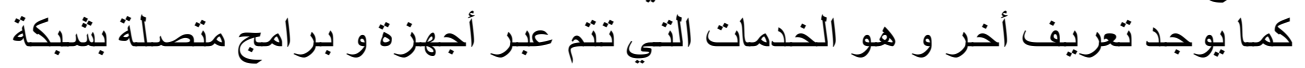

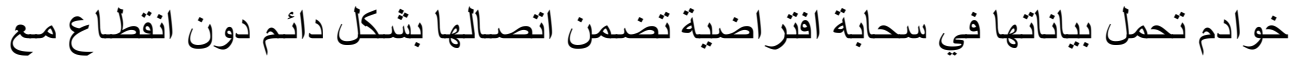

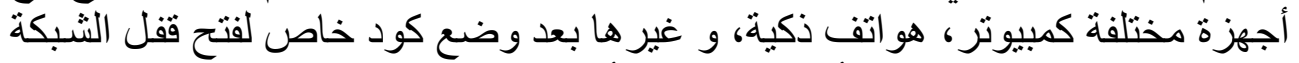

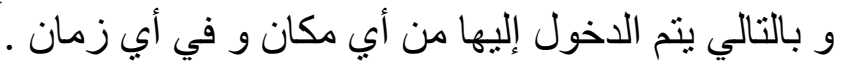

${ }^{23}$ Pentecost,Michael j .2014.bigdata. 
الثورة الصناعية الرابعة و أدواتها

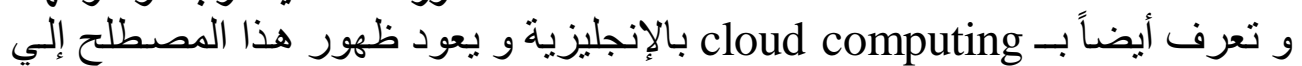
الستينيات و ذللك عندما بدأت بعض الثركات بالتفكير بمدي الفائدة التي ستحقى جراء

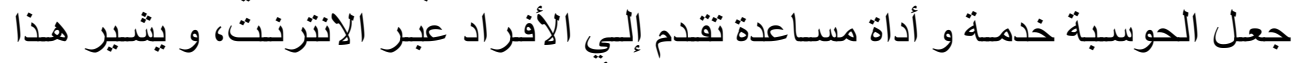

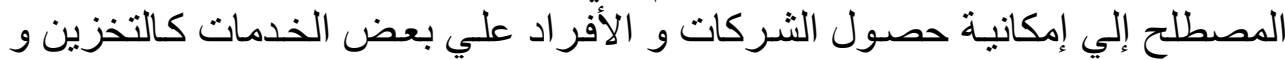

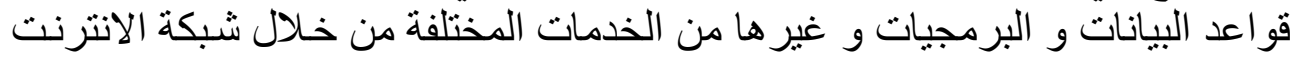

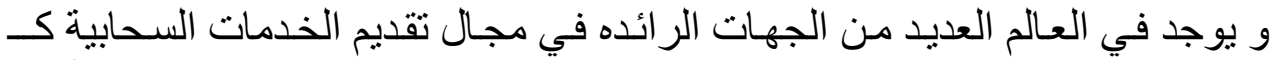
Google Cloud PlatForm

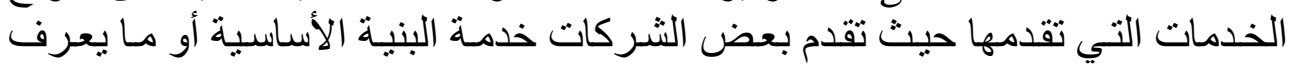

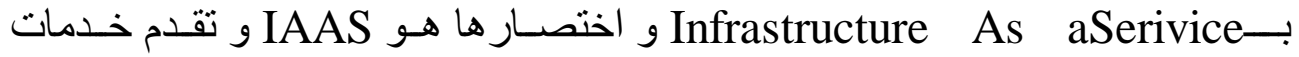
التخزين عبر الانترنت من خلال هذا النوع من الخدمات السحابية و هو as a Service

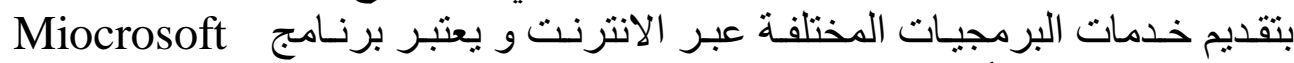
office 365 ? إذا ما هو الـ SAAS يتشـارك البرمجيـات التثلاث في أنهم نمـاذج للحوسبة علي أسـاس الخدمـة و فيمـا يلي شر ح كل علي حده:-

أولاً : البنية التحتية كخدمة

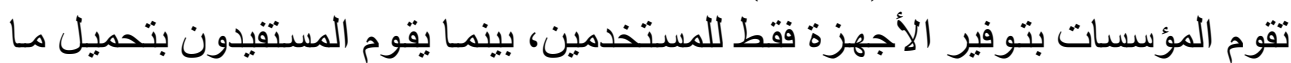

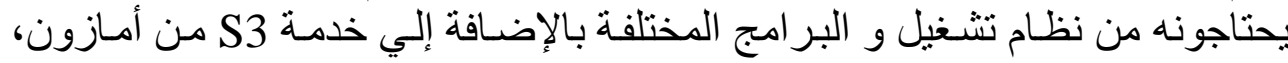
وبذلك فتعتمد هذه الطبقة علي توفير العتاد التي تمثل البنية التحتية فقط دون الخو ادم و

غير ها.

ثانياً : المنصة كخدمة Platform as a service (PAAS) ثندة

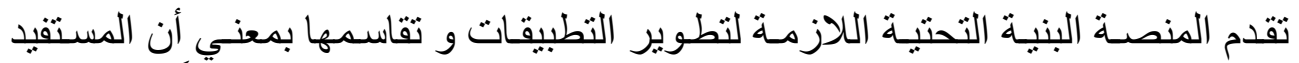

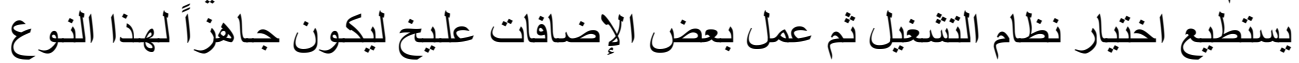

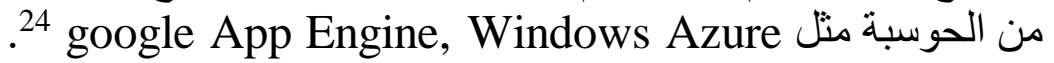
Software as a service (SAAS) ثالثاً :البرمجيات كخدمة

24 البسيوني، بدوية محمد.2015.بر مجيات الحوسبة السحابية و دور ها في تطوير خدمات

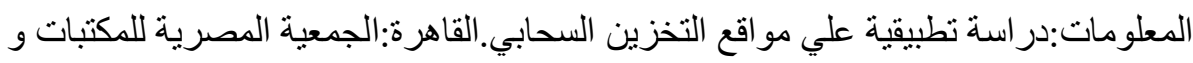

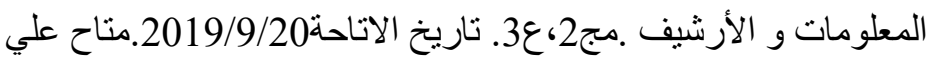
http://search.mandumah.com/677920 علي 
د الد / نهال أحمد الشاذلي

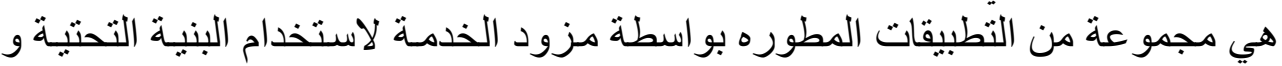

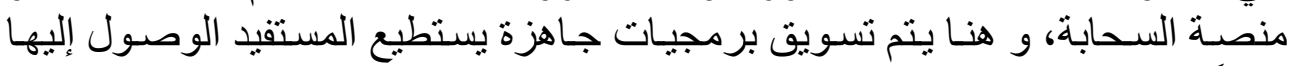

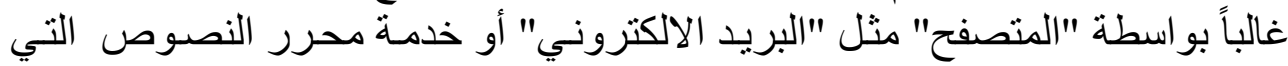

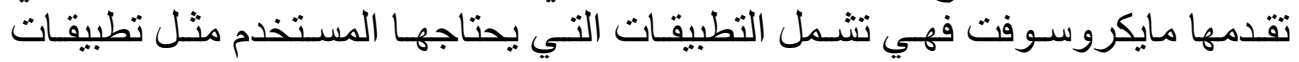
مايكروسوفت و تطبيقات جوجل. 25

و تتعد تطبيقات الحوسبة السحابية و التي ستذكر ها الباحثة في السطور القليلة القادمـة

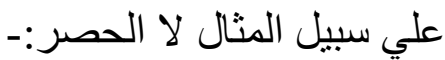

Sky Drive

Windows live

Microsoft office

Google chrome os

Windows Azure

Pixlr editor

Google docs

Jaycut

Aviary music creator

1 .خدمة تقدمها شركة مايكروسوفت لجميع المشتركين بهاو هي : Windows live

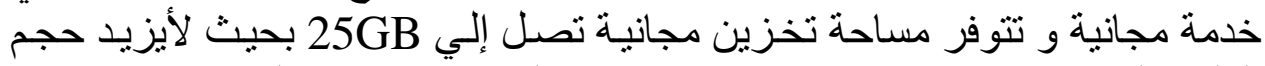

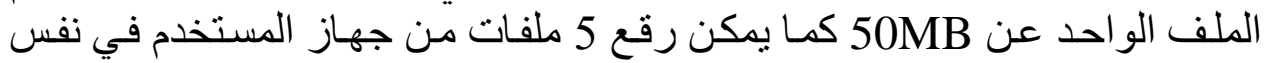

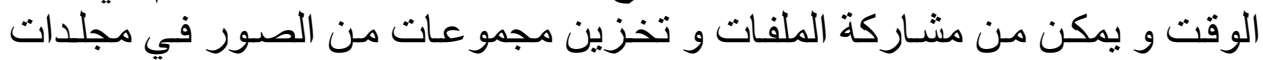

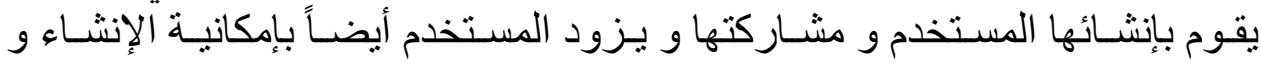

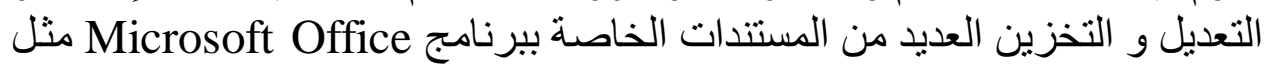

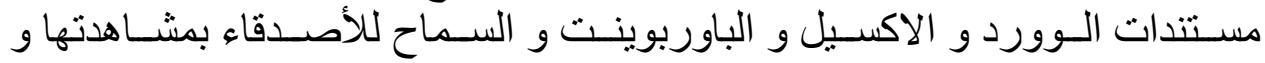

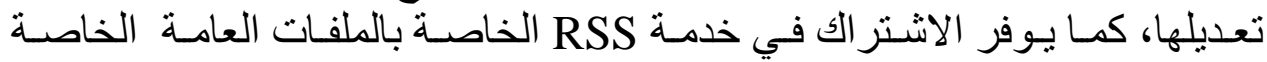

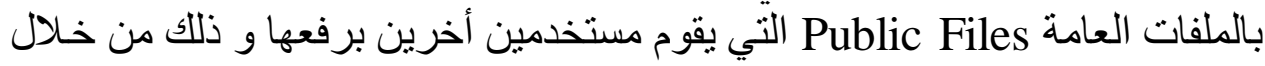

${ }^{25}$ Altahat,Khalid .suliman, taha.2018.moving towards the cloud.

المؤتمر الرابع و العشرون :البيانات الضخمة و آفاق استثمار ها : الطريق نحو التكامل

المعرفي.مسقط:جمعية المكتبات المتخصصة فرع الخليج العربي. تاريخ الاتاحة

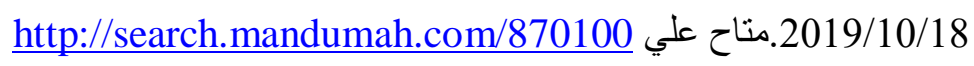


الثورة الصناعية الرابعة و أدواتها

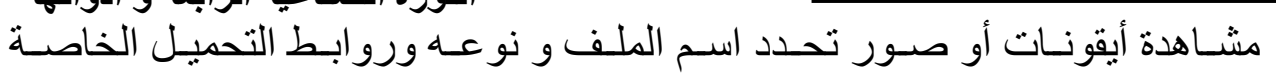
بالملفات 26

: Google Chrome OS .2

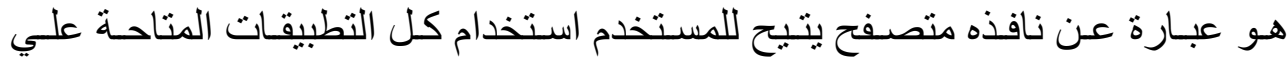

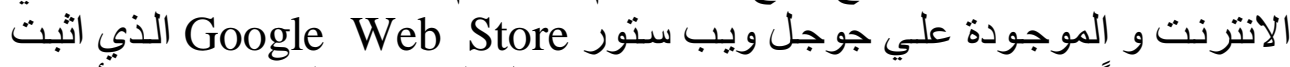

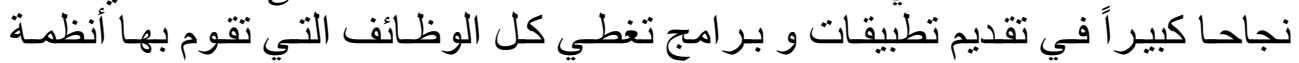
التشغيل العادية بداية من كتابة رسائل التذكير و حتي في إنتاج الأفلام.

: Windows Azure .3

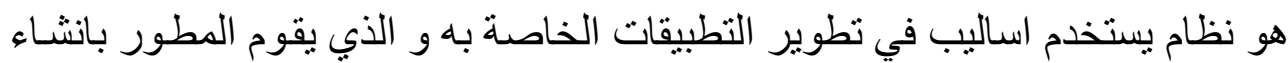

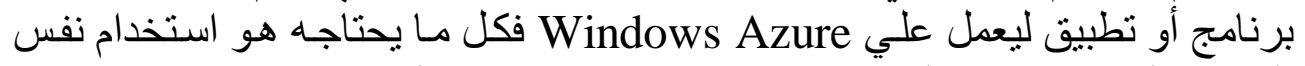

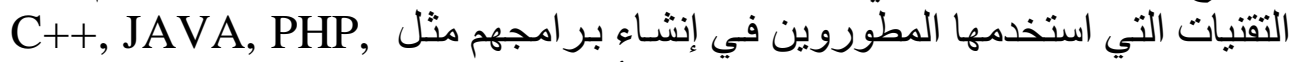
Microsoft SQL أنهيعتمد علي تقليل الوقت المستخدم.

: Pixlr editor .4

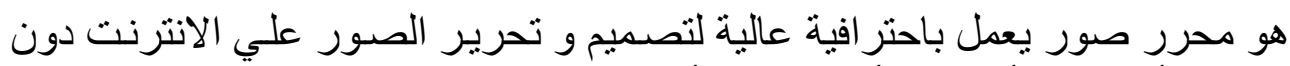

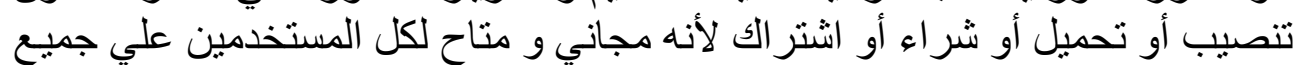

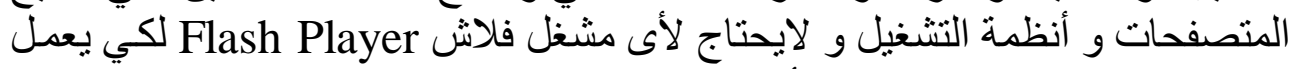

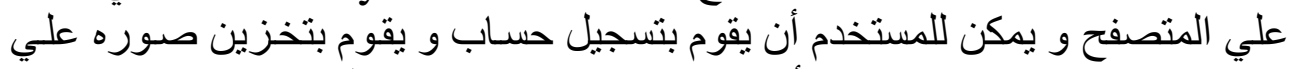

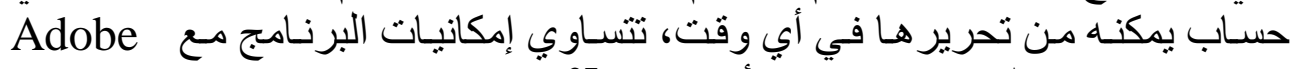
Photo Shop

خدمات الحوسبة (2019). متاح علي :

https://almaarik.wordpress.com/\%D8\%A7\%D9\%84\%D8\%AD\%D9\%88\%D 8\%B3\%D8\%A8\%D8\%A9-

\%D8\%A7\%D9\%84\%D8\%B3\%D8\%AD\%D8\%A7\%D8\%A8\%D9\%8A\%D 8\%A9-\%D9\%81\%D9\%8A-

\%D8\%A7\%D9\%84\%D8\%AA\%D8\%B9\%D9\%84\%D9\%8A\%D9\%85cloud-computing-in-education/

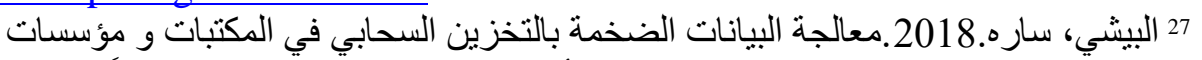

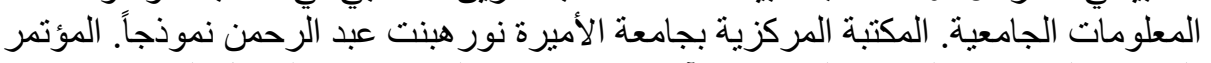

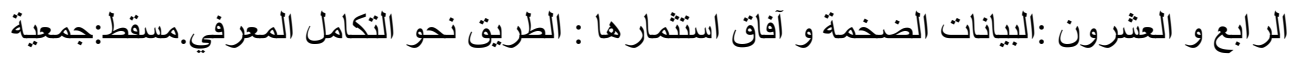

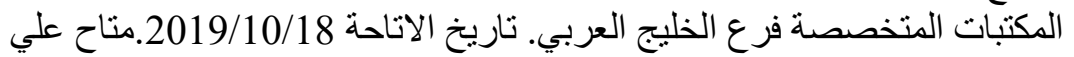
http://search.mandumah.com/870344 


\section{د / مهال أحمد الثناذلي}

: Google Docs .5

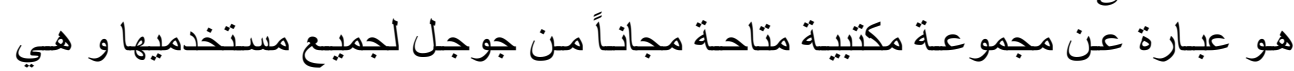

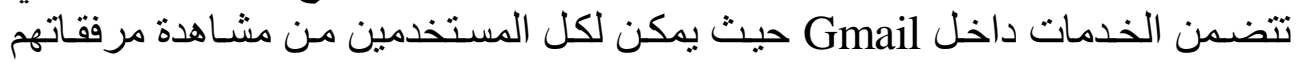

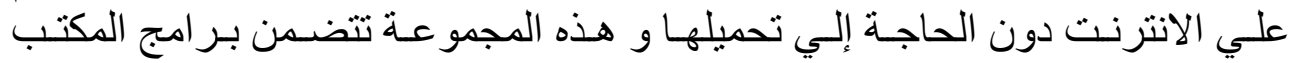

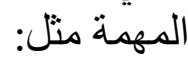

للكتابة، عمل عروض تقديمية، عمل جداول حسابات المخططات، الاستبانات، و كل مل بلات

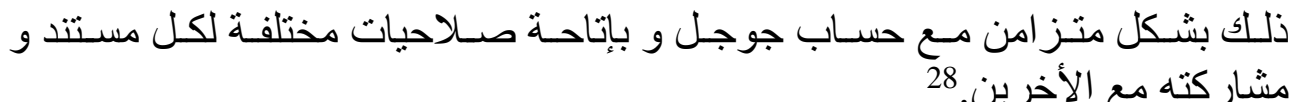

:Jaycut .6

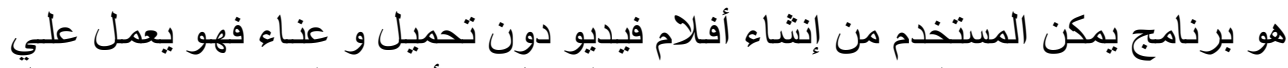

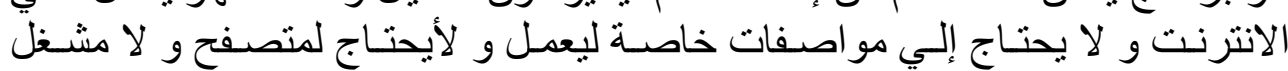

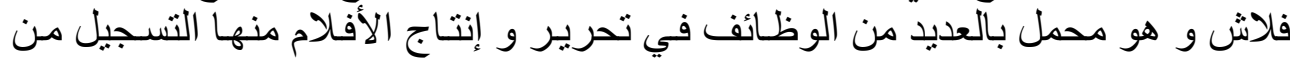

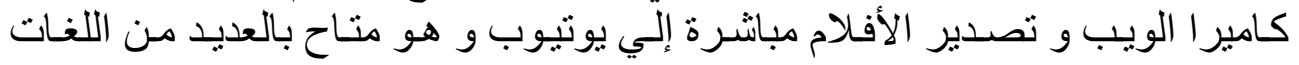
لسهولة الاستخدام

: Aviary Music Creator .7

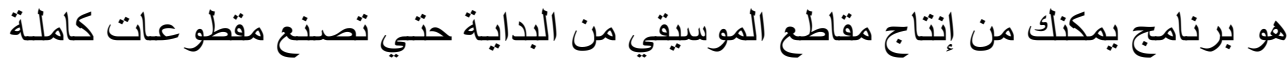

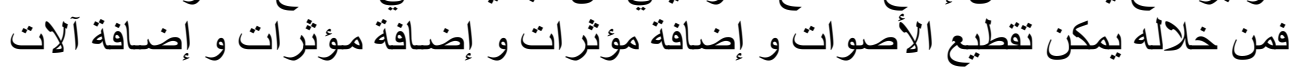

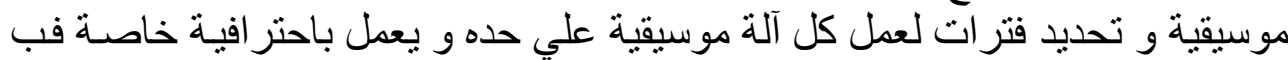
عالم برامج إنتاج الموسيقي و هو نموذج ناجح لبرامج الوسئ الوسائط المتعددة و التي تعدل علي السحاب علي شبكة الآنترنت .

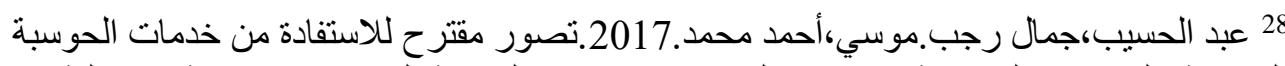

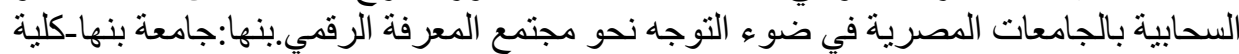

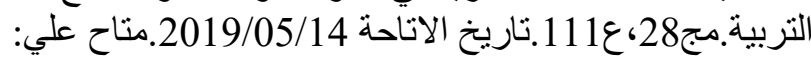
http://search.mandumah.com/861653

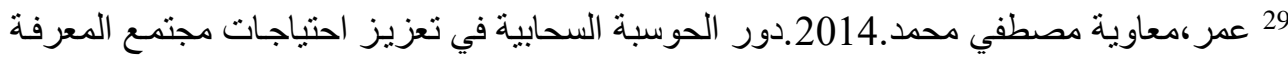

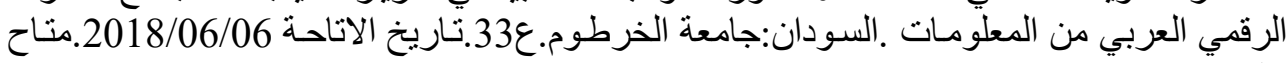

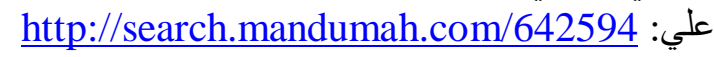

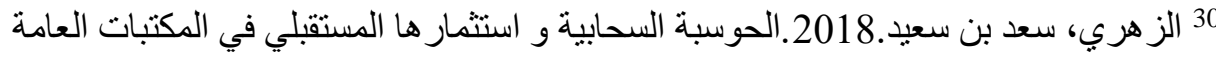

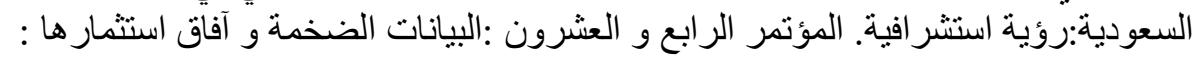

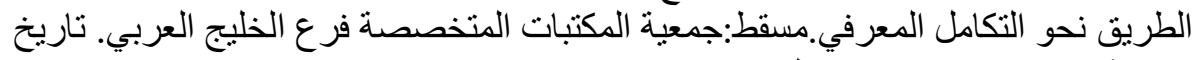

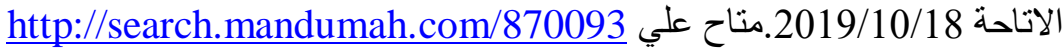


الثورة الصناعية الرابعة و أدو اتها

$$
\text { 2/6مميزات الحوسبة:- }
$$

1. الدخول إلي البيانات من أي مكان تتو افر فيه خدمة الانترنت .

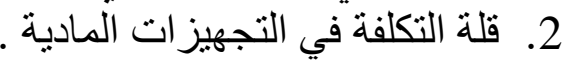

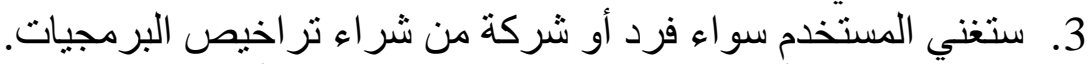

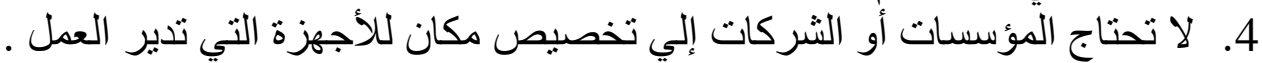

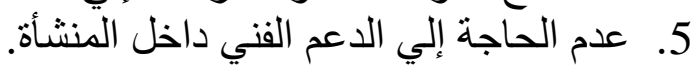

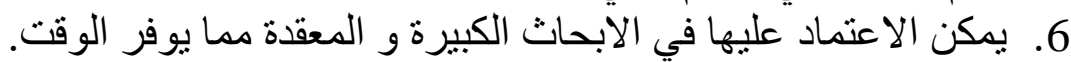
7. 8. اصية المشاركة للملفات و التي تخفض التخاطي المساحة التخزينية .

9.

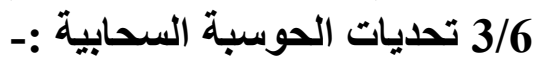
1. الحاجة إلي مساحة تخزينية كبيرة.

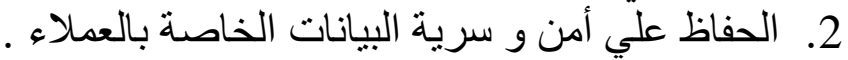
3. تو افر التطبيقات المناسبة لجميع المؤسسات و جدواهية الها الاقتصادية . 4. تو افر التغطية الثاملة للوصول السريع للانترنت .

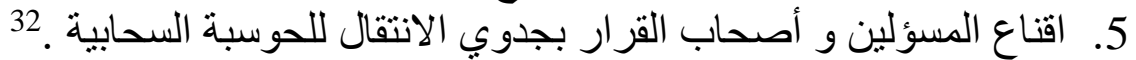

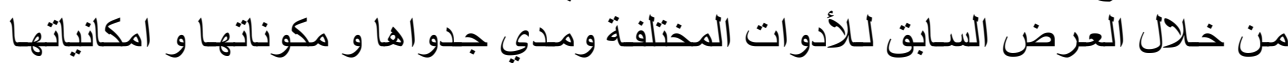

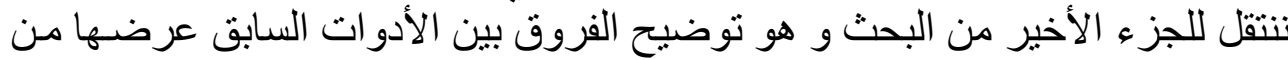

\begin{tabular}{|c|c|c|c|}
\hline Nosql & Saphana & Hadoop & وجه المقارنة \\
\hline$\sqrt{ }$ & - & - & لا تتبع تصميم ثابت \\
\hline$\sqrt{ }$ & $\sqrt{ }$ & $\sqrt{ }$ & المرونة \\
\hline
\end{tabular}

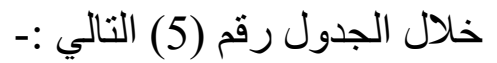

$$
\text { : علـ }
$$

$$
\text { ـز ات الحوسـ }
$$

https://mawdoo3.com/\%D9\%85\%D8\%A7_\%D9\%87\%D9\%8A_\%D8\%A7 \%D9\%84\%D8\%AD\%D9\%88\%D8\%B3\%D8\%A8\%D8\%A9 \%D8\%A7\%D 9\%84\%D8\%B3\%D8\%AD\%D8\%A7\%D8\%A8\%D9\%8A\%D8\%A9

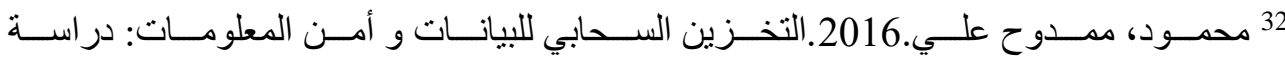

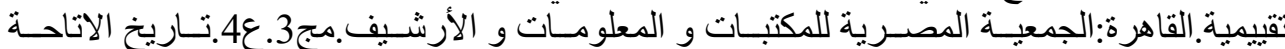

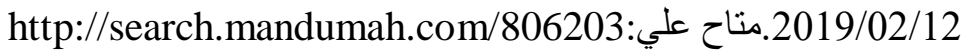




\begin{tabular}{|c|c|c|c|}
\hline Nocol & Sanhon & Hodoon & 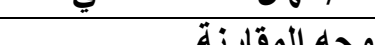 \\
\hline 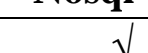 & pos & $P$ & الآت سي \\
\hline$\sqrt{ }$ & $\sqrt{ }$ & $\sqrt{ }$ & تكلفة اقا \\
\hline$\sqrt{ }$ & $\sqrt{ }$ & $\sqrt{ }$ & تصحبح المشاكل تلقائياً \\
\hline$\sqrt{ }$ & $\sqrt{ }$ & $\sqrt{ }$ & معالجة البيانات الثابتة \\
\hline$\sqrt{ }$ & $\sqrt{ }$ & $\sqrt{ }$ & سرعة معالجة البيانات \\
\hline - & $\sqrt{ }$ & - & Olap \\
\hline - & $\sqrt{ }$ & - & Oltp \\
\hline - & $\sqrt{ }$ & - & المعالجة داخل الذاكرة \\
\hline$\sqrt{ }$ & $\sqrt{ }$ & - & الاسترجاع بالملفات \\
\hline$\sqrt{ }$ & $\sqrt{ }$ & $\sqrt{ }$ & المعالجة المتوازية \\
\hline$\sqrt{ }$ & $\sqrt{ }$ & $\sqrt{ }$ & مفتوح المصدر \\
\hline$\sqrt{ }$ & $\sqrt{ }$ & $\sqrt{ }$ & التعامل مع البيانات الضخمة \\
\hline 11 & 13 & 10 & المجموع \\
\hline$\% 78.57$ & $\% 92.85$ & $\% 71.42$ & النسبة \% \\
\hline
\end{tabular}

تفوق برمجيات الـsap hana علي منافسيها بمعدل ممتاز و ذلك لتو التو افر جميع أنواع

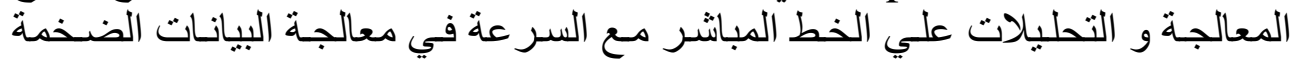

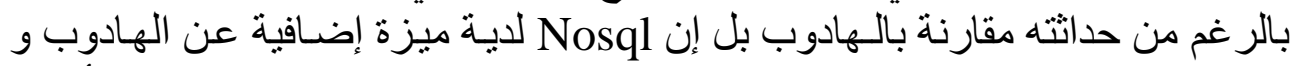

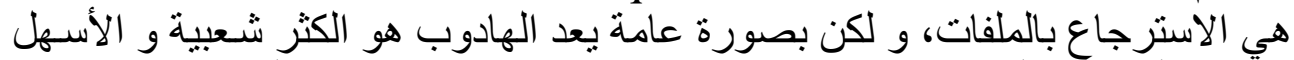

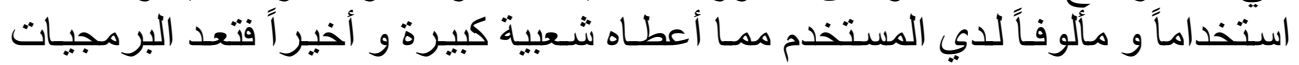

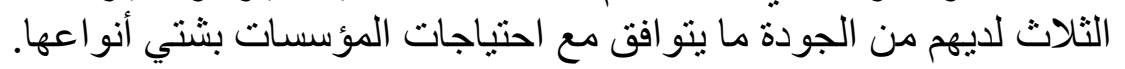

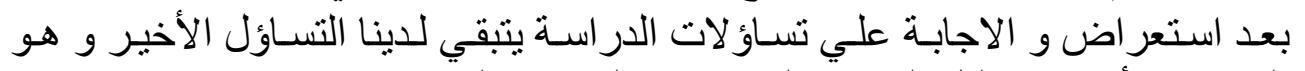

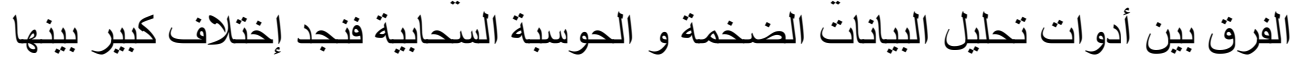

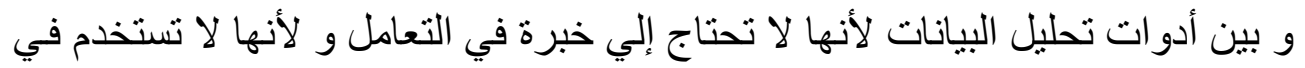

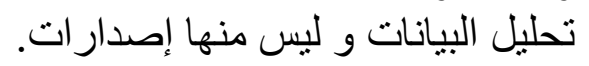

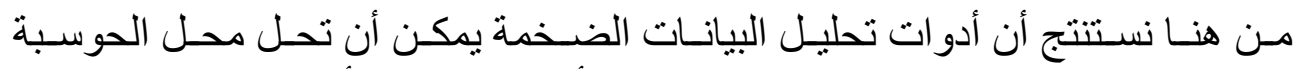

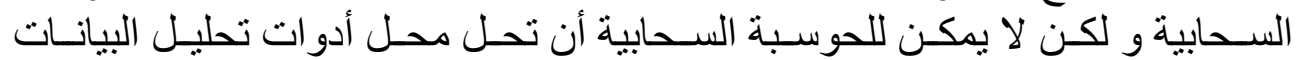
الضخمة .

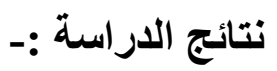
تثمثل نتائج الار اسة في النقاط التالية :- نئ 
الثورة الصناعية الرابعة و أدو اتها

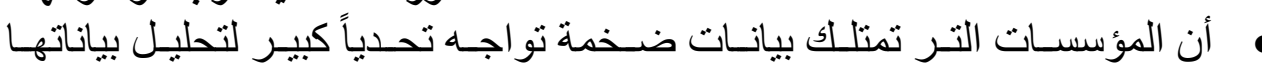
بأنثكالها المختلفة سواء المهيكلة أو غير المهيكلة.

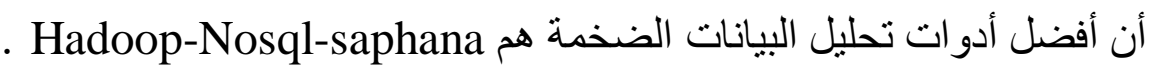

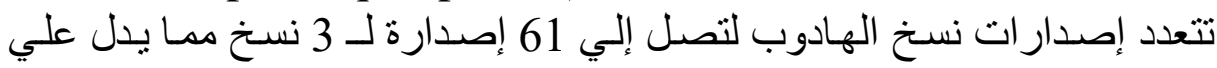

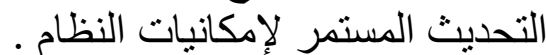

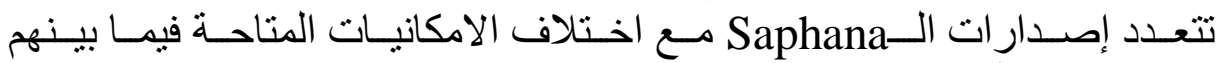

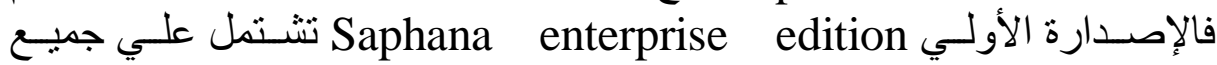

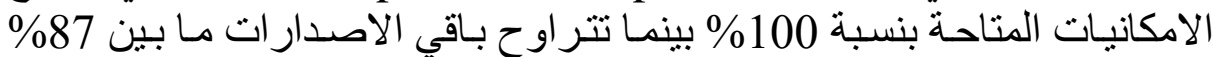
إلي 93\% و هي نسبة جيدة جدا أيضاً.

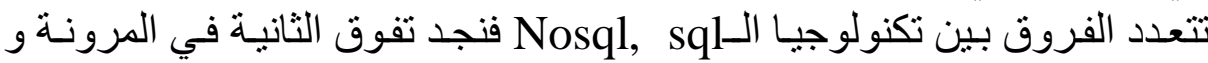

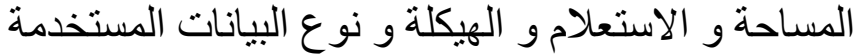

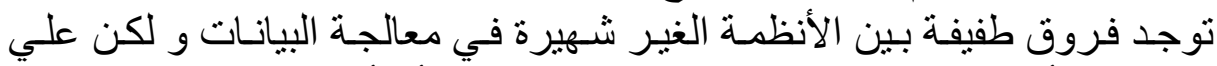

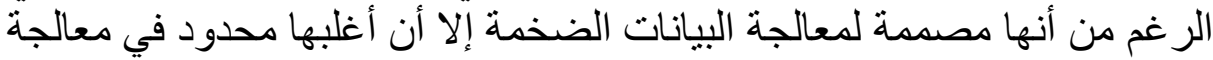

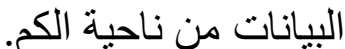

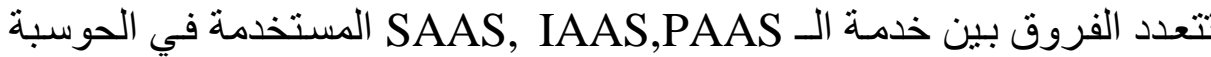
السحابية فالأولي (SAAS) هي الأكثر ميزة لتوفير البرمجيات كخدمة للمستفيد.

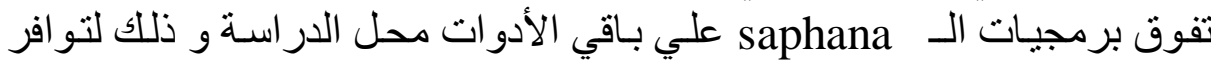

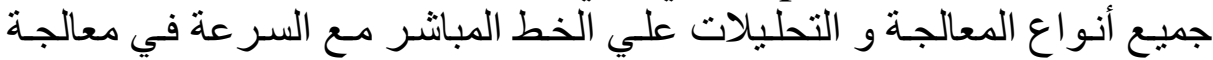

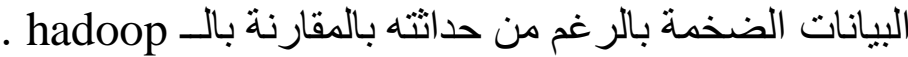

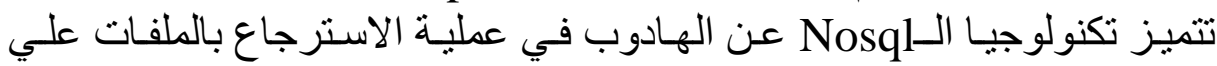

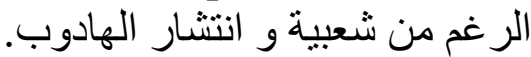

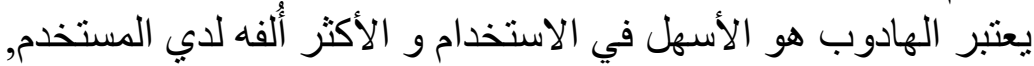

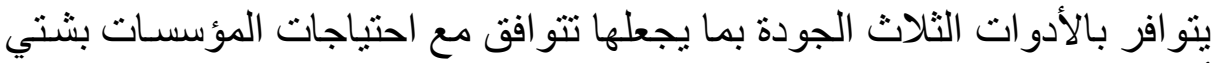
أنو اعها.

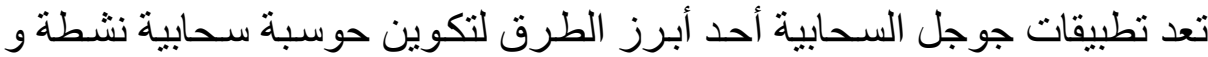

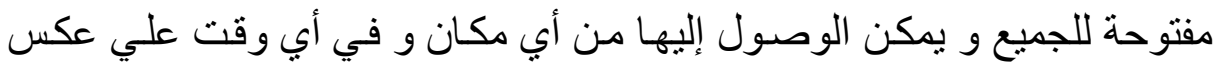

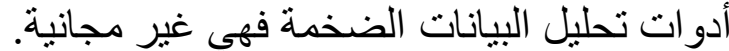

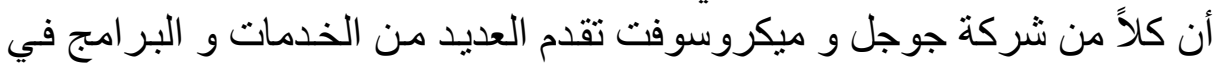

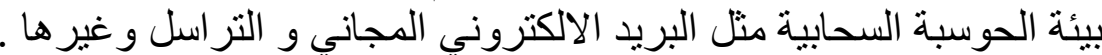

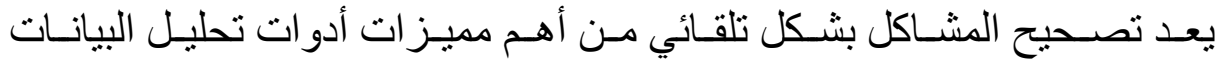
الضخمة و الدنو افرة في أدوات الدر استة. أن أدوات تحليل البيانات الضخمة ئركن ألن أن تحل محل الحوسبة السحابية و ليس

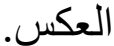




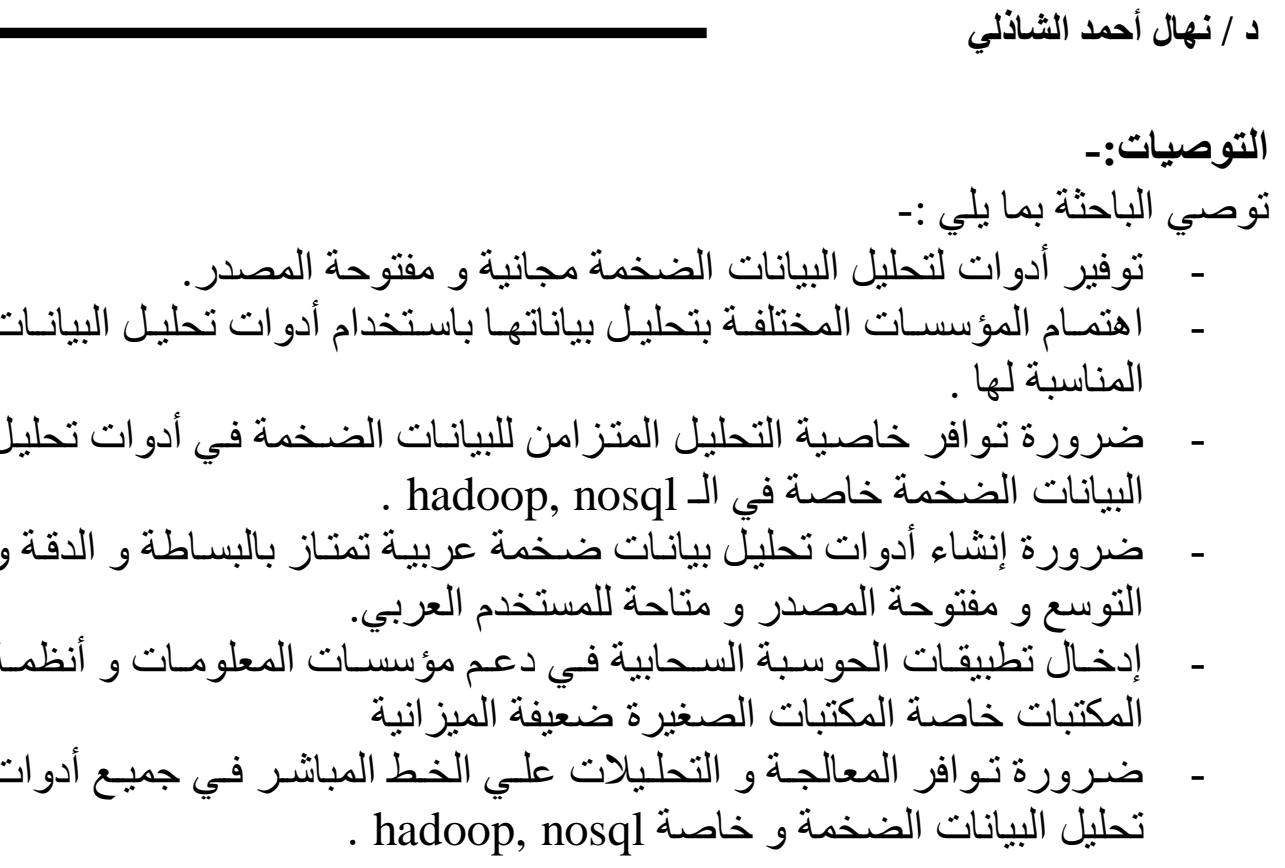

قائمة المراجع و المصادر:-

1. Mira, Hasan .Sap hana (2019).available at :

https://www.youtube.com/watch?v=OFEwPwdIKW0

2. A Comparison Of NoSQL Database Management Systems And

Models(2019) available

at:https://www.digitalocean.com/community/tutorials/a-comparison-of-

nosql-database-management-systems-and-models

3. Altahat,Khalid .suliman, taha.2018.moving towards the cloud. 
الثورة الصناعية الرابعة و أدواتها

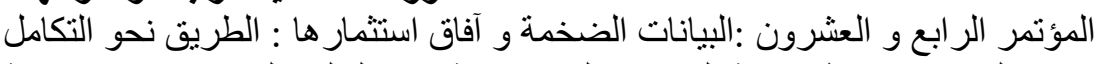

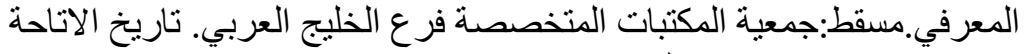

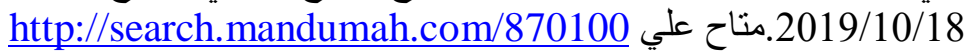

4. Biceuska, zane.oditis,Ivo.2017.towards nosql-based data warehouse solutions date27/07/2018.available at :

http://creativecommons.org/licenses/by-nc-nd/4-01

5. Chandra, dekaganesh.2015.base analysis of nosql database.date18/12/2018available at : http://www.elsevier.com/locate/f9cs

6. Corbellini, alejandro2017.persisting big-data:the nosql

landscape.date18/12/2018 availanle at : www.elsevier.com/locate/Infosys

7. Hamad, $\mathrm{f}(\ldots$.etal).2018.bigdataand analytics strategies in academic

libraries:opportunities and challenges,the case of the university of Jordon

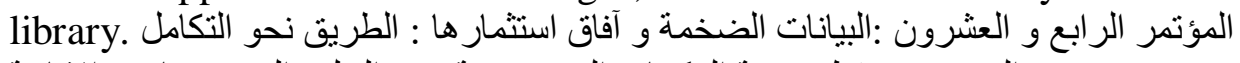

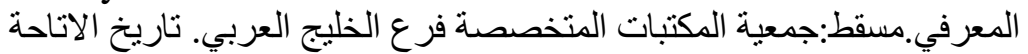

2019/10/18http://search.mandumah.com/870281

8. Lakhe, bhushon.practical hadoop security:friends of apress.

9. Leetaru,kalew h.2018.the user of future bigdata and remaginig how we think

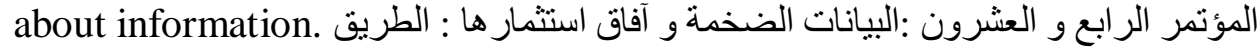

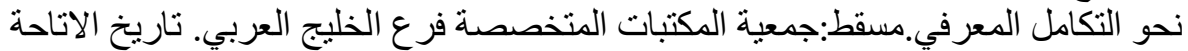

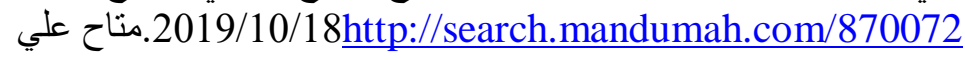

10. Pentecost,Michael j .2014.bigdata.

11. Sap hana (2019). available at: https://www.youtube.com/watch?v=7RSSy7Azvr0

12. Saphana(2019). Available at :http://hana.sap.com/abouthana.html

13. Wadkar, Sameer,...etal.pro apache hadoop.friend of apress.

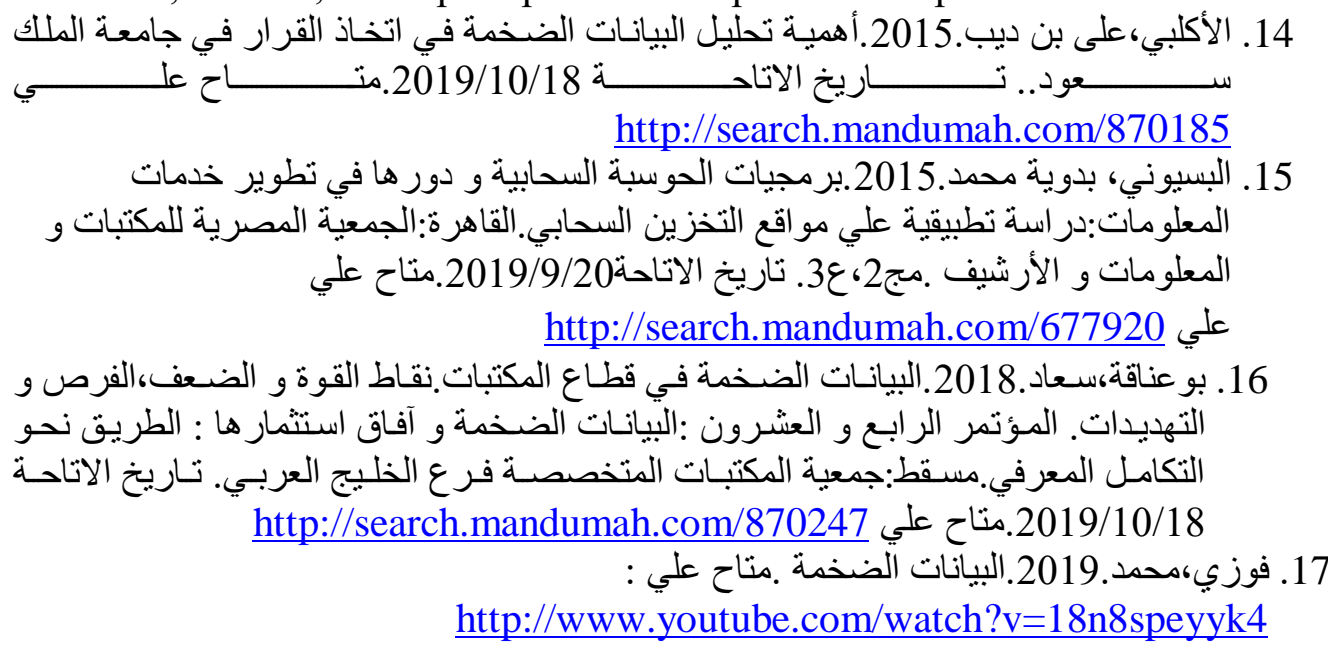




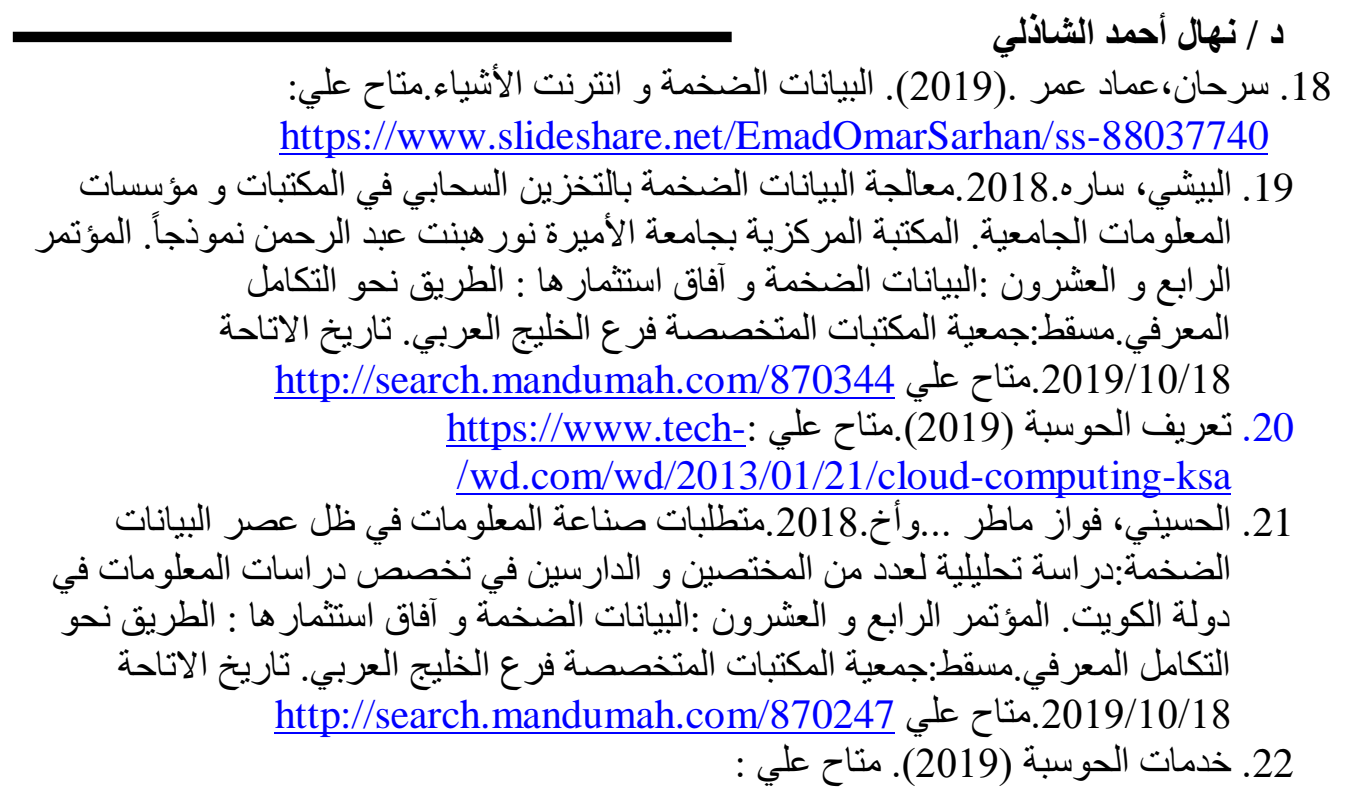

https://almaarik.wordpress.com/\%D8\%A7\%D9\%84\%D8\%AD\%D9\%88\%D 8\%B3\%D8\%A8\%D8\%A9-

\%D8\%A7\%D9\%84\%D8\%B3\%D8\%AD\%D8\%A7\%D8\%A8\%D9\%8A\%D $8 \%$ A9-\%D9\%81\%D9\%8A-

\%D8\%A7\%D9\%84\%D8\%AA\%D8\%B9\%D9\%84\%D9\%8A\%D9\%85cloud-computing-in-education/

23. خليفة،زينب محمد حسن.2015.الحوسبة السحابية خدماتها و دور ها في العملية التعليمية

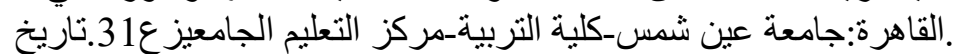

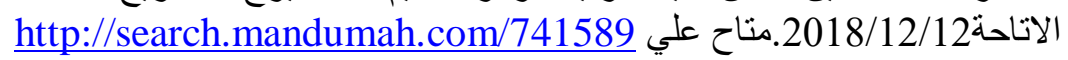

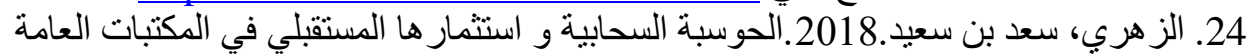

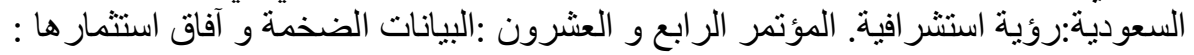

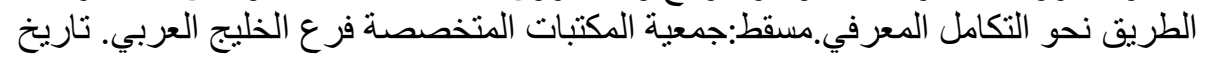

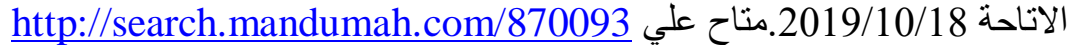

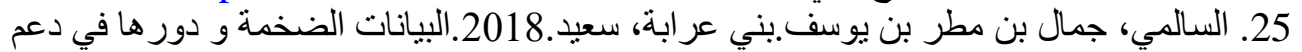

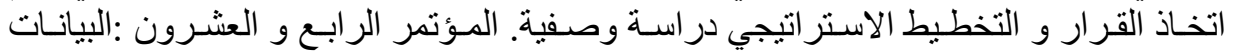

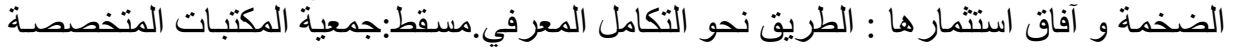

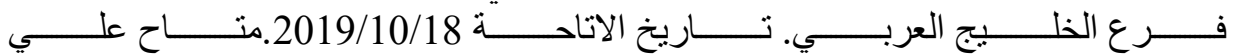

http://search.mandumah.com/870077

26. السالمي،خلود بنت خالد بن سليمان.الهنوية، هاجر سليمان ناصر .2018. 27077 اقع استخدام البيانات

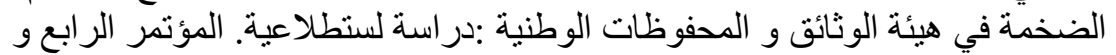

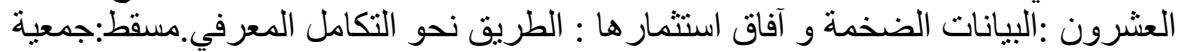

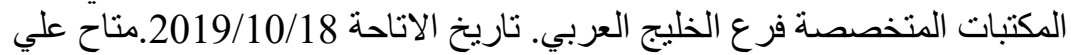

http://search.mandumah.com/870085 
الثورة الصناعية الر ابعة و أدواتها

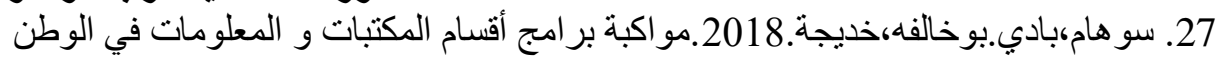

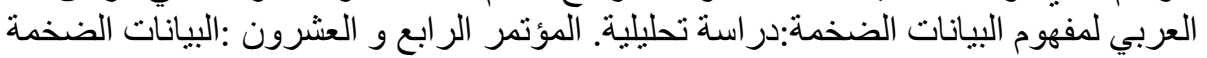

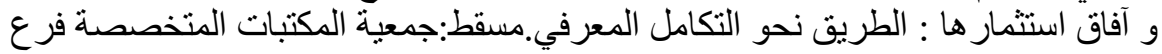

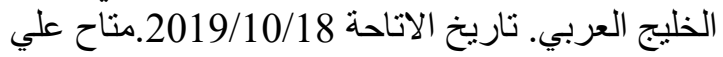
http://search.mandumah.com/870112

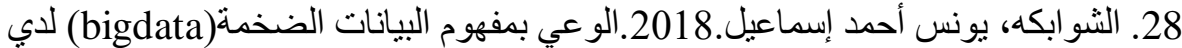

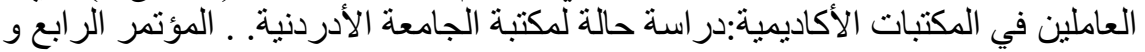

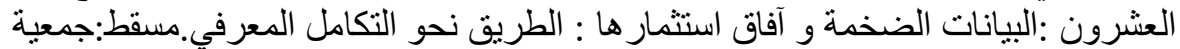

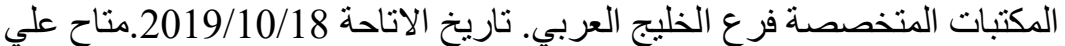

http://search.mandumah.com/870244

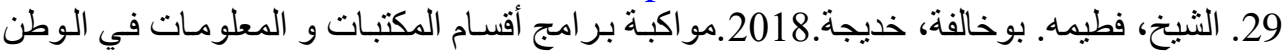

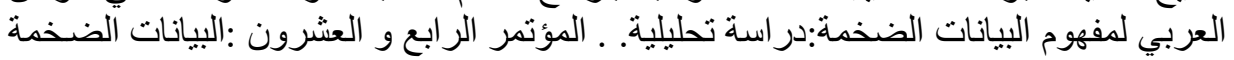

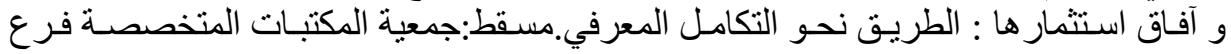

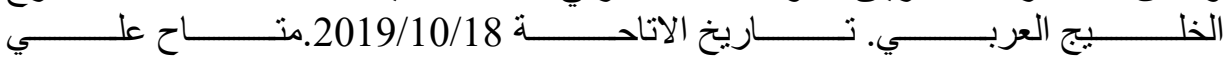
http://search.mandumah.com/870112

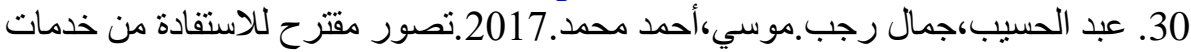

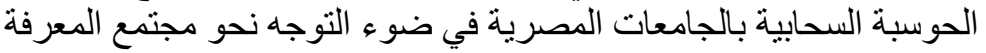

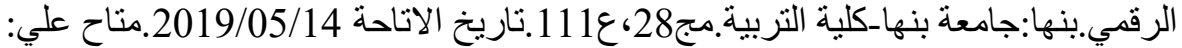

http://search.mandumah.com/861653

31. عبد القادر،أمل حسين.2018.إسهام البيانات و المعلوماتوات في التنمية المستدامة:رؤية مستقبلية.

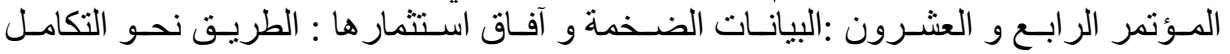

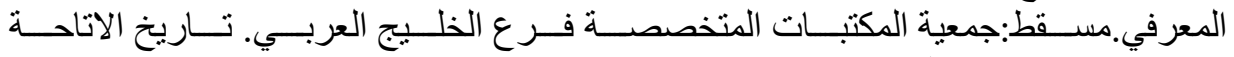

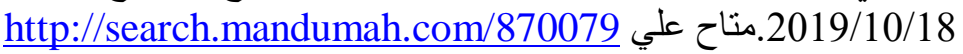

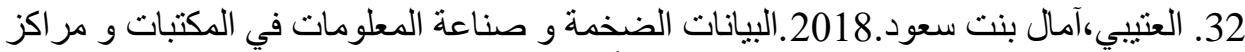

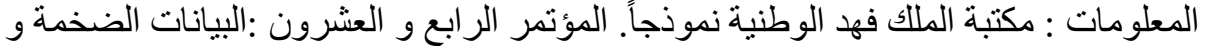

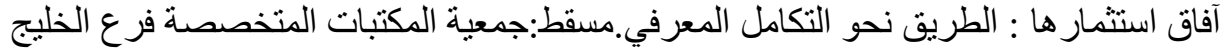

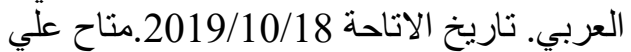
http://search.mandumah.com/870339

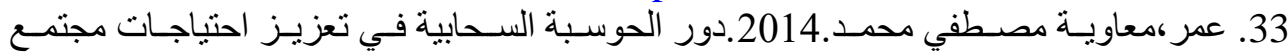

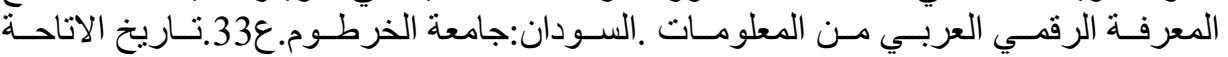

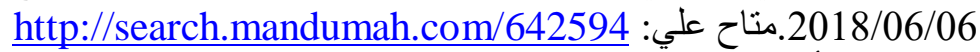

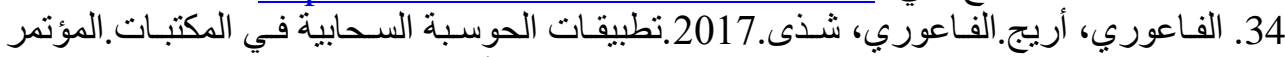

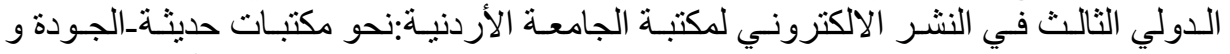

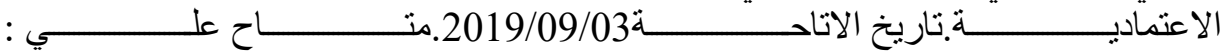
http://search.mandumah.com/837307

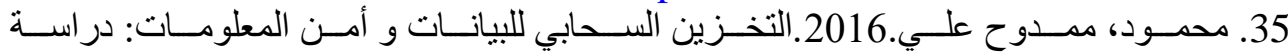

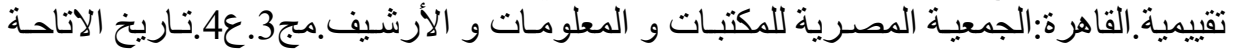

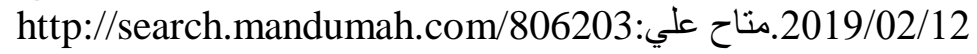




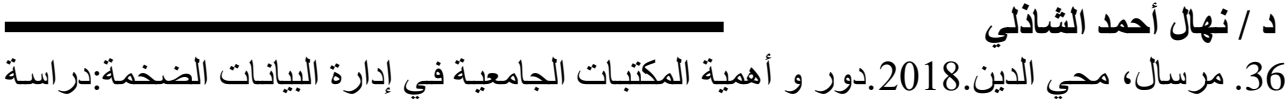

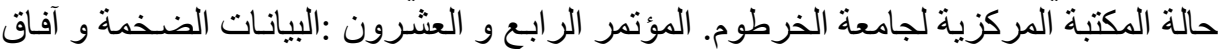

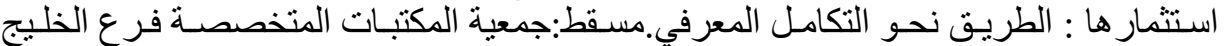

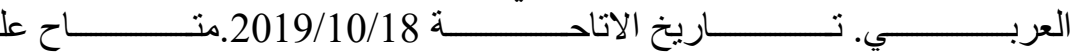
http://search.mandumah.com/870188

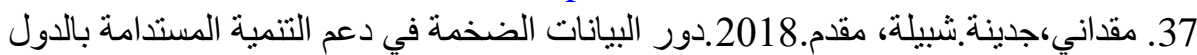
العربية. المؤتمر الرابع و العشرون :البيانات الضخمة و آفاق استثمار ها : الطريق نحو التهاتئة التكامل

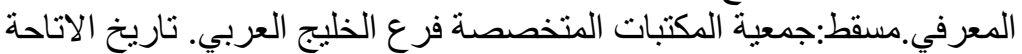

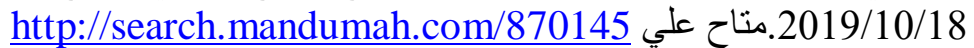

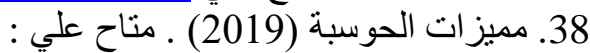

https://mawdoo3.com/\%D9\%85\%D8\%A7 \%D9\%87\%D9\%8A \%D8\%A7 \%D9\%84\%D8\%AD\%D9\%88\%D8\%B3\%D8\%A8\%D8\%A9 \%D8\%A7\%D 9\%84\%D8\%B3\%D8\%AD\%D8\%A7\%D8\%A8\%D9\%8A\%D8\%A9

39. https://

https://www.facebook.com/OpenitEG/photos/a.218684984974491.1073

741828.202314549944868/463163927193261/?type=1\&theater

40. https://ar.karizma.io/\%D8\%A3\%D9\%87\%D9\%85\%D9\%8A\%D8\%A9-

\%D8\%AA\%D8\%AD\%D9\%84\%D9\%8A\%D9\%84-

\%D8\%A7\%D9\%84\%D8\%A8\%D9\%8A\%D8\%A7\%D9\%86\%D8\%A7\%

D8\%AA-\%D8\%A7\%D9\%84\%D8\%B6\%D8\%AE\%D9\%85\%D8\%A9-

\%D9\%88\%D8\%A3\%D8\%A8\%D8\%B1\%D8\%B2-

$\% \mathrm{D} 9 \% 85 \% \mathrm{D} 9 \% 86 \% \mathrm{D} 8 \% \mathrm{~B} 5 /$

41. https://www.sap.com/dam/application/shared/images/chartsdiagrams/sap-hana-product-structure.png.adapt.800 -

1.false.false.true.false.png

42. //:itwadi.com/Apache Hadoop

\begin{tabular}{|c|c|}
\hline تاريخ الاطلاق & الاصدار \\
\hline 2019 & 3.2.0 \\
\hline 8 أغسطس 2018 & 3.1.1 \\
\hline 2018 مايو 2018 & 3.0.1 \\
\hline 3 مايو 2018 & $\underline{2.9 .1}$ \\
\hline 15 مايو 2018 & 2.8 .4 \\
\hline
\end{tabular}




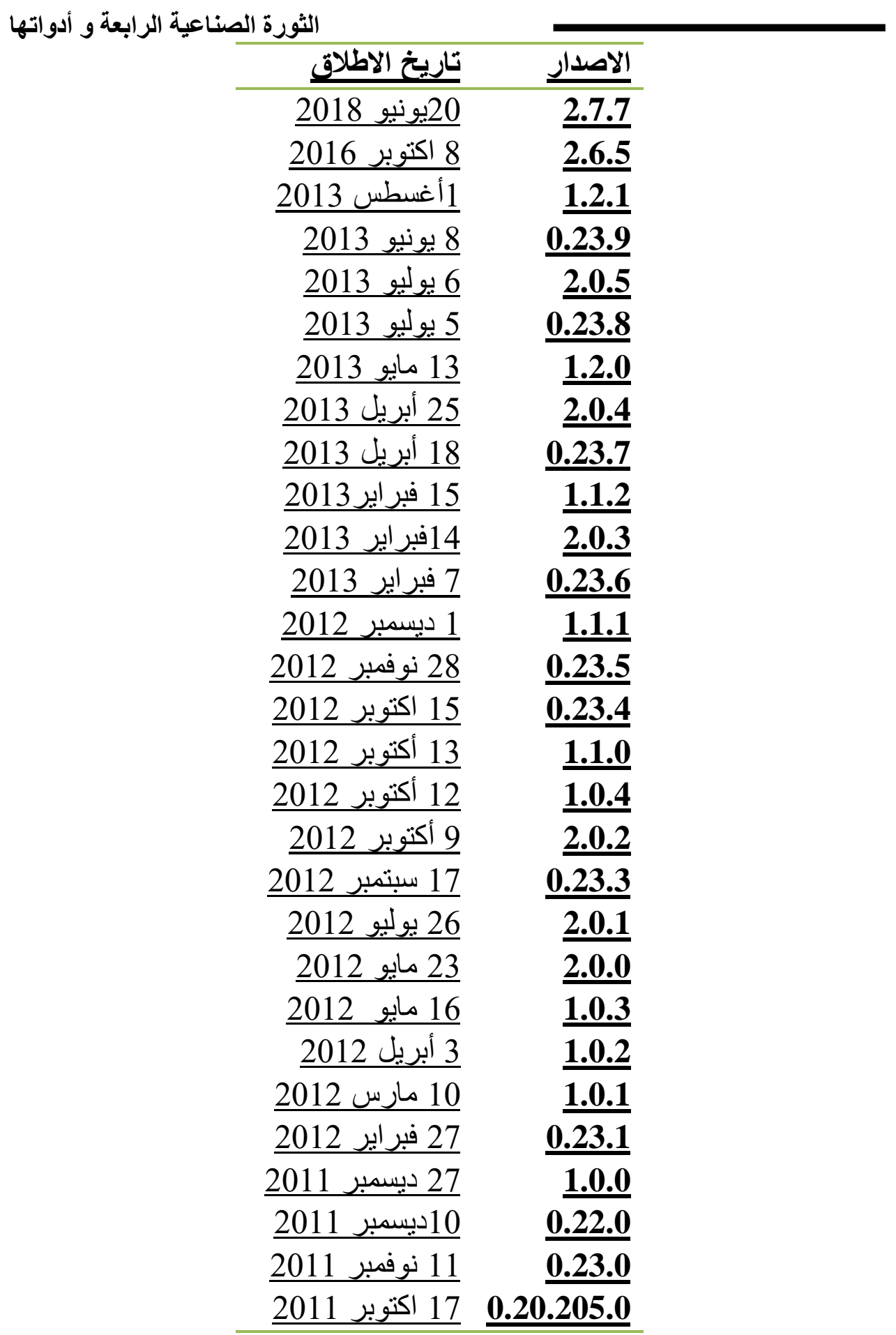




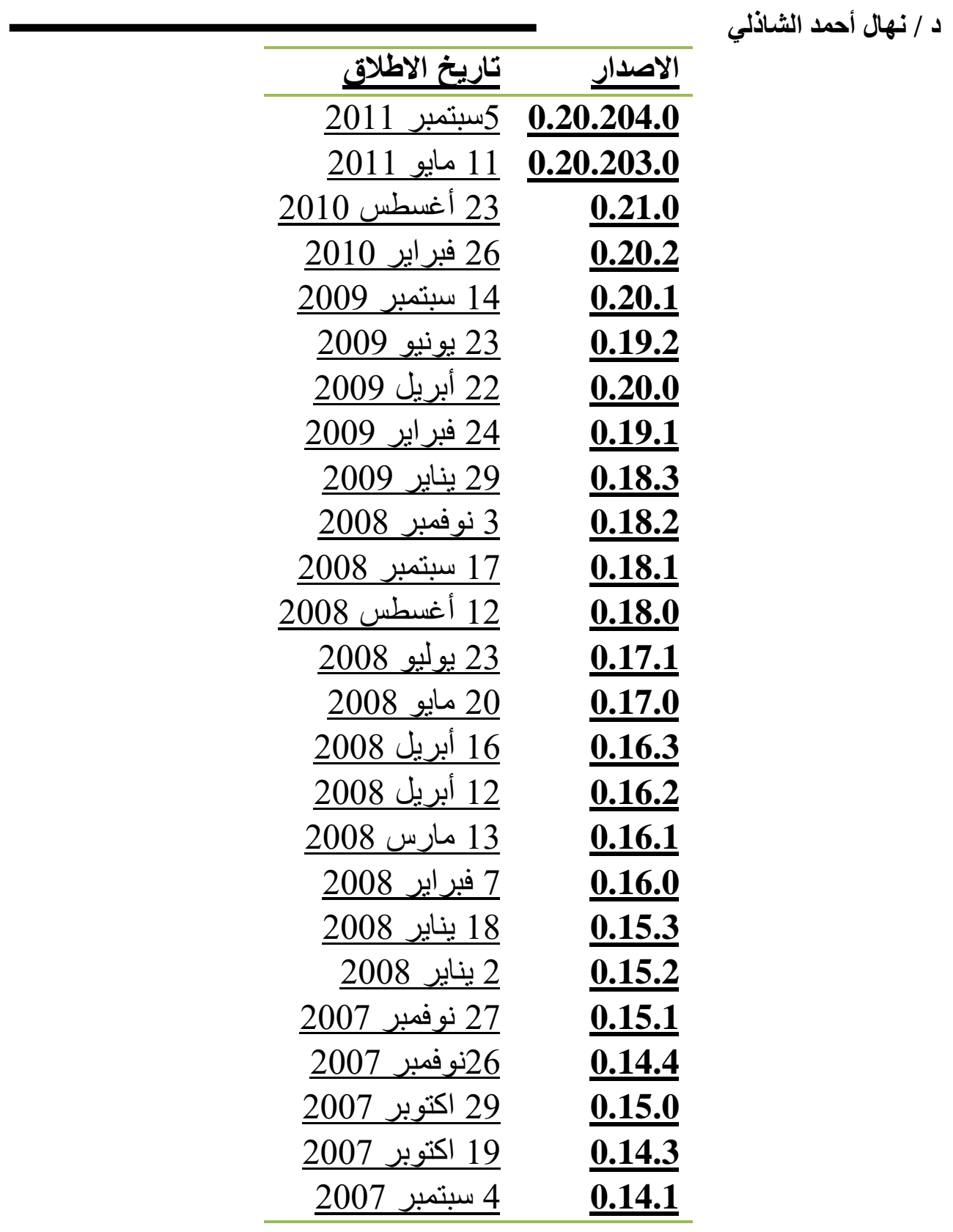

abstract 
الثورة الصناعية الرابعة و أدواتها

This study boils down to Identify several big data analysis tools And the selection of the most famous and most important of the three tools they are HADOP-SAB HANA-NoSQL To make a comparison and deduce the highest quality and the best And show the percentage in between The results showed a strong convergence between the three tools Despite sabhana's progress over the other two tools However, the three tools still share many advantages And the study referred to some terms that are used in the research Which the reader listens to like cloud computing Some people may be confused by the existence of convergence between them and data analysis tools However, with the review of the term, it was found that there is no comparison between them because they do not participate in any of the indicators.

Inclouded ${ }^{1}$

${ }^{2}$ Not inclouded

${ }^{3}$ Only for sap applications

${ }^{4}$ optional 